IV.

Aus der II. medizinischen Universitätsklinik zu Berlin (Direktor: Geh.-Rat Prof. Dr. Fr. Kraus).

Experimentelle Beitråge zur neueren Leukåmietherapie.

Von

Prof. Dr. A. Pappenheim.

(Hierza Tafol I.)

Einleitung.

Einer der interessantesten Abschnitte der Pathologie ist das Kapitel der Leukämie.

Wie die ganze moderne Hämatologie sozusagen auf dieses Kapitel zugeschnitten ist und von ihm immer wieder von neuem angeregt und befruchtet wird, so bemühen sich auch ausser Bacteriologie und Toxicologie die Klinik, experimentelle Pathologie und Therapie um die Klärung dieses noch absolut dunklen Gebietes.

Das Wesen der leukämischen Affektion besteht wie bekannt in einer blinden unlimitierten und daher dysteologischen (nicht reaktiven) byperplastischen Wucherung hämopoëtischen Gewebes.

Diese Wucherung ihrerseits besteht in schrankenloser Vermehrung der Stammzellen des hämopoëtischen Gewebes, zugleich mit differentieller Umbildung derselben zu reifen lıämocytoblastischen Parenchymgewebszellen, ja sogar unter Umbildung dieser auch zu reifen Blutzellen, also in einer wirklichen echten Hyperplasie aller parenchymatösen hämopoëtischen Gewebsbestandteile; indessen ist die differentielle Umbildung zu reifen Gewebs- und-weiter zu Blutzellen doch geringer als die wuchernde Vermehrung der unreifen Stammzellen; und je akuter der Prozess verläuft, desto mehr tritt die Differenzierung hinter der Wucherung zurück ${ }^{1}$ ) (Pappenheim), so dass in den perakuten Leukämieformen reife Gewebsund Blutzellen nur ganz vereinzelt gefunden werden, dafür aber eine fast ausschliessliche Vermehrung unreifer Stammzellen [sogen. Entdifferenzierung ${ }^{2}$ )].

Eine weitere Eigentümlichkeit der leukämischen und ihr verwandten stärker infiltrativ wachsenden Affektionen (Chlorome, Myelome, Lymphosarkome Kundrat) ist einmal ihre Beschränkung auf den hämopoëtischen Apparat, ferner das diffuse Ergriffensein desselben, so dass man heutzutage nach dem Vorschlage des Autors ${ }^{3}$ ), dem sich besonders $\mathrm{Naegeli}$

1) of. Pappenheim, Zeitschr. f. klin. Med. Bd. 47. S. 52. - Alfred Wolf, ebenda. Bd. 45. - L. Michaelis, ebenda. Bd. 45. - Klieneberger, Deutsche med. Wochenschr. 1909. Nr. 49. - Carl, Medizinische Klinik. 1910. - Steffler, Deutsches Arcb. f. klin. Medizin. Bd. 106. 14,330

2) Ueber die Stellung der akuten Leulämie usw. F'ol. haem. 1907. Bd. 4. S.11,

3) Ebenda. 
angeschlossen hat ${ }^{1}$, die leukämischen Affektionen als ngeneralisierte Systemerkrankungen" bezeichnet.

Drittens ihr mehr oder weniger stark infiltratives Wachstum, welches besonders stark bei den oben letztgenannten hierhergehörigen Affektionen, den Lymphosarkomatosen, den Myelomen und Chloromen ausgeprägt ist. Dass diese mit den eigentlich leukämischen Affektionen trotzdem eng verwandt und keine echten Tumoren sind, wird durch mindestens histologische Uebergänge erwiesen. Dic Myelome zeigen alle Uebergänge zur sogen. medullären Pseudoleukämie (aleukämische medulläre Lymphadenie), Baumgarten, Runeberg, Senator, Domarus, Rubinstein). Die Chlorome, welche allein Sternberg allerdings wegen ihres infiltrativen Wachstums als Leukosarkomatosen auffasst, gehen vielfach mit leukämischer Alteration des Blutes und Charcot-Leydenscher Kristallbildung einber. Und schliesslich verlaufen gelegentlich auch die Lymphosarkomatosen blutleukämisch, wie durch gewisse klassische Fälle z. B. von Straus-Virchow ${ }^{2}$ ) bewiesen wird.

Es sind diese leukämischen Sarkoidgeschwülste also keine echten Sarkome mit Bildung anaplasierter echter metastasierender Tumorzellen, sondern sie sind nur eine besondere Erscheinungs- und Manifestationsart der leukämischen Affektionen und eng zu ihnen gehörig als sarkoleukämische Affektionen. Durch sie aber haben die Leukämien ihre gewissen Beziehungen auch zu den echten „Malignomen“.

Während wir über die Histologie, die cytologischen Befunde, den klinischen Verlauf dieser Erkrankungen im grossen und ganzen wohl unterrichtet sind, ist absolut dunkel die Aetiologie.

In gewisser Hinsicht Beziehungen mit den echten malig nen Tumoren zeigend, verhalten sie sich in anderer Hinsicht auch wieder recht ähnlich mit den generalisierten In fektionsgranulomen des hämopoëtischen Apparates, wie der Lymphdrüsentuberkulose und der ihr verwandten sogen. Lymphogranulomatosis. Die Verwandtschaft ${ }^{3}$ ) mit den malignen Tumoren ist abgesehen von der gleichen Beeinflussbarkeit durch Arsenikalien und Röntgenstrahlen gegeben durch das Schrankenlose der Wucherung als solcher, bei der sogar die differentielle Zellumwandlung zu funktionstüchtigen Zellen unter der Akuität des Prozesses leidet; allerdings kommt es nicht zur Bildung rassenfremder echter morphologisch, biologisch anaplasierter Tumorzellen; was bei der Entdifferenzierung entstebt, sind schliesslich mindestens in morphologischer und wohl auch zellbiologischer

1) Blutkrankheiten und Blutdiagnostik. 1908.

2) Cbarité-Annalen. Bd. XXIII. 1898.

3) Nambafte Pathologen wie Banti (Zeitschr. f. Path., 1904) und Kibbert (Deutsche med. Wochenschr., 1907) betrachten sogar die Leukämie direkt für einen sarkomatös metastasierenden Prozess.

Uns scheint das zu weit gegangen; böchstens kann man sagen, dass die leukämischen Affoktionen an hämopoëtischen Apparat ein Aequivalent für jene blastomatösen Vegetationen sind, die am sonstigen mesenchymatischen Stroma durch die Sarkome repräsentiert werden. Auch hier gibt es Unterschiede. Die Endotheliome nehmen ebenso unter den Sarkomen eine Sonderstellung ein, wio die Cancroide unter den epithelialen Carcinomen. 
Hinsicht normale Körpergewebszellen, also normale hämocytoblastische Elemente, nur im unreifen Zustande.

Eine solche unreife Gewebszelle verhält sich zur reifen Gewebs- und schliesslich zur Blutzelle, wie die Spermatogonie zur Spermatide und schliesslich zur Spermie

Auch die angeblichen lymphatischen Leukosarkomzellen Sternbergs und die Zellen der Kundratschen Lymphosarkome sind schliesslich als von nicht-tumoröser Natur erkannt und nur als unreife normale Myeloidzellen bezw. Lymphocyten nachgewiesen worden ${ }^{1}$ ). Auch darin unterscheiden sich die hierhergehörigen Prozesse von echten malignen Tumoren, dass wahre Metastasen, Propagation des Prozesses durch sekundäre Zellverschleppung nicht beobachtet wird ${ }^{2}$ ) auch bei der sogen. Kundralschen Lymphosarkomatose scheinen echte Metastasen einwandfrei noch nicht nachgewiesen zu sein. Vielmehr metastasiert hier, wie bei den infektiösen Prozessen, der ursächliche hyperplastische Reiz als solcher, die unbekannte externe Noxe, sodass es sich nur um eine Multiplizität von Primärwucherungen handelt.

Dagegen ist bei diesen Prozessen durchweg ein geringeres, bei einem Teil der hierher gehörigen Erkrankungen sogar ein äusserst stark infiltratives und aggressives Wachstum, ganz wie bei den echten bösartigen Sarkomen, beobachtet worden (Lymphosarkome, Leukosarkome, Chlorome, Myelome), sodass man hier sogar vielfach von einem Uebergang in echte Malignität spricht und die infiltrativ wacbsenden Prozesse als sarkoleukämisch bezeichnet ${ }^{3}$ ).

Man könnte auf den Gedanken kommen, dass es eine Besonderheit der Parenchymzellen des hämopoëtischen Apparates, also der Stammund Mutterzellen der Blutzellen sei, nicht in echter Weise maligne (zur Metastasenfähigkeit) zu entarten, sondern sozusagen auf halber Stufe biologischer Malignität stehen zu bleiben, derart, dass die Zellen zwar schrankenlose Fortpflanzungsfähigkeit und infiltrative Aggressivität erlangen, nicht aber die Befähigung zur echten Metastasenbildung. Demgegenüber würde es sich, im Gegensatz zu diesen Sarkoleukämien und Lymphosarkomen des Gewebsparenchyms, bei den echten Lymphdrüsensarkomen, den primären Sarkomen, ausgehend von den stromatischen Reticulum- und Endothelzellen, um echte Sarkome handeln. Es wären also die den leukämischen Parenchymerkrankungen verwandten Lymphosarkome zu trennen von den primären stromatischen Drüsensarkomen und den sekundären Sarkomen im Lymphdrüsengewebe, ebenso wie die primären Myelome von den primären und sekundären Myelosarkomen.

Wenn die Unfähigkeit zur echten tumorösen Entartung eine Besonderheit der Parenchymzellen des homopoëtischen Apparates wäre, dann würden derartige leukämische und verwandte Erkrankungen hier

1) Pappenheim, Folia. IX.Archiv, 1910. - Graetz, Zieglers Beitr. Bd. XIX.

2) Zwar wird von mehreren Forschern (Helly, Ziegler, früher Ehrlich) die myeloide Umwandlung der Milz auf colonisierende Innidation metastasenartig verschleppter normaler Knochenmarkzellen bezogen.

3) cf. Hierzu die zusammenfassenden und übereinstimmenden Berichte von v. Domarus u. A, Herz. Fol. haematol. Bd. XIII. 1912. 
sozusagen das Aequivalent der tumorösen Erkrankung anderer Körperzellen vorstellen, und es würde hier vielleicht eine gute Handhabe gegeben sein, dem Wesen und der Aetiologie der echten Tumoren auf die Spar zu kommen. Mehren sich doch gewisse Indizien, dass es sich bei den echten Tumoren um den Coeffekt $z$ weier Faktoren handelt, einer spezifischen internen tumorösen Disposition der Körperzellen, der wahren eigentlichen Ursache der Tumorbildung, bedingt durch Anlage, Vererbung, erworbene Veranlagung, Störung der internen Sekretionsverhältnisse, wie Alter usw., und eines zweiten äusserlichen unspezifischen, bloss auslösenden, occasionellen Momentes, wie chronische Reize mechanischer, chemischer, radiologischer, toxischer und infektiöser Natur. (Paraffinkrebs, Pfeifenkrebs, Röntgenkrebs.)

Wenn es sich aber bei der Tumorgenese wirklich um den Coeffekt zweier Faktoren handeln sollte, deren einer die völlig unbekannte interne Disposition wäre, dann allerdings müsste bis jetzt die experimentelle Forschung wach künstlicher Erzeugung maligner Primärtumoren durch Applikation verschiedenster unspezifischer äusserer Reize scheitern. An der vorhandenen ätiologischen Mitwirkung auch äusserer Reize können indes aber selbst die strengsten Anhänger der Cohnheim-Ribbertschen Theorie nach den überzeugenden älteren Beobachtungen Virchows (Paraffinkrebs, Pfeifenkrebs, Oesophagus-Säuferkrebs) und den neuesten Beobachtungen von Röntgencarcinomen wohl kaum zweifcln. Wie zuerst B. Fischer durch seine schönen Untersuchungen mit Scharlachöl dargetan hat und Borst und seine Schüler (Schmincke) später weiter ausgeführt und bestätigt haben, scheinen die sogen. „Attrexine ${ }^{*}$, welche nach Fischer eine atypische Wucherung der Epithelzellen zur Folge haben, gewisse lipoidlösliche Stoffe von äusserst schwachem Reizvermögen zu sein, ähnlich wie I. $L$ öb in seinen berühmten cytologischen Studien eine feinste partielle Lipolyse oder lipatische Andauung der Lipoide der Zellmembran als einleitende Ursache der Lokomobilität und Zellteilung erkannt hat. Dass unter solchen Umständen gelegentlich auch infektiöse Noxen von äusserst schwachem Reizvermögen bei chronischer Wirkung auf einen dazu disponierten Organismus tumoröse Wucherung auslösen können, kann a priori nicht von der Hand gewiesen werden.

Wie aber bei der experimentellen Verpflanzung von Tiertumoren ein äusserst grosses Versuchsmaterial zur Verfügung stehen muss, um in einem gewissen Prozentsatz unter hunderten von Versuchstieren ein Angehen des Transplantates bei dazu prädisponierten Individuen zu erzielen, so werden auch bei der experimentellen Erzeugung von Primärtumoren die entsprcchenden Versuche mit einer externen Ursache an einem viel grösseren Versuchsmaterial wie bisher und mit toxisch viel abgeschwächteren Ursachen vorgenommen werden müssen.

Erwähnt sei jedenfalls, dass der berühmte Rattentumor von Jensen, seiner histologischen Natur nach ein Sarkom, der in seiner Descendenz auch heute noch in hunderten von Laboratorien fortgezüchtet wird, primär von Jensen selbst ursprünglich zufällig durch ein säurefestes Stäbchen erzielt worden war.

Ob nun aber die Anschauung, dass die leukämischen Affektionen mit 
den malignen Affektionen gewisse Verwandtschaft haben, im Laufe der Zeit weitergestützt oder erschüttert werden wird, die Ansicht, dass die leukämischen Prozesse mit den entzündlich infektiösen Prozessen gewisse Beziehungen teilen, wird heute wohl von der Mehrzahl der massgebenden Pathologen geteilt.

Es gibt nämlich auch nachweislich infektiöse Prozesse, die wie die leukämischen Affektionen anf (|rn hämopoëtischen Apparat elektiv beschränkt sind, hier in Form ebenfalls einer Systemerkrankung und ebenfalls in einer Multiplizität von Primärherden bestehen, und schliesslich ebenfalls einen abortiven Ansatz zum Uebergang in histologische Malignität durch atypisches Wachstum erkennen lassen. Es sind das die generalisierte Lymphknotentuberkulose und die Lymphogranulomatose Sternbergs. Beide histologisch und gewebsbiologisch (verschiedenes Verhalten gegen Tuberkulinreaktion) mehr oder weniger different, haben das gemeinsam, dass bei ihnen ein ätiologisches Agens nachgewiesen ist, bei der Tuberkulose der Kochsche Bacillus, auch in der grampositiven granulären Form von Much; bei der Lymphogranulomatose ebenfalls säurefeste Stäbchen, vorläufig noch unbekannter Natur (Dietrich, Hirschfeld, Arndt, Oskar Meyer), die ebenfalls in granulärer gramfester Modifikation vorkommen (Eugen Fränkel und Much). Obwohl auch bei ihnen Uebergänge zu infiltrativem Wachstum beobachtet worden sind, die man als Uebergänge zu Lymphdrüsensarkom (fälschlich Lymphosarkom) glaubte deuten zu sollen (Yamasaki, Dietrich), so ist doch ihnen, im Gegensatz zu den leukämischen Affektionen, eigentümlich die Mitbeteiligung des Stroma (Fibroblasten, Plasmazellen, Epitheloidzellen, endotheliogene Megakaryocytoidzellen), welche gemeinhin den reaktiven entzündlich granulierenden Prozessen eigentümlich ist. Die Verwandtschaft der leukämischen Affektionen mit diesen letzteren Prozessen wird dadurch noch grösser, dass einmal auch bei letzteren gelegentlich chloromatöse Verfärbung zur Beobachtung gelangt (Benda), die sich sonst nur bei den leukämischen Affektionen findet; dass andererseits auch bei den leukämischen Prozessen Ausgänge in Fibrose und Knochensklerose zur Beobachtung kamen [Heuck, v. Baumgarten, M. A skanazy ${ }^{1}$ ), Webb ${ }^{2}$ )], welche eine Art A usheilungsprozess anzeigen und das Vorhandensein reaktiver Vorgänge als wahrscheinlich nahe legen. Dass ferner der auf die symmetrischen Gesichtsdrüsen beschränkte Morbus Miculicz oft chloromatös und hier bald rein parenchymatös-lymphocytomatös, bald mehr stromatisch-granulomatös in die Erscheinung tritt. Vor allem aber, dass nicht nur bei den aleukämischen Myelomen und Myelolymphomen, sondern auch bei den echten Leukämien plasmocytäre Formen beschrieben sind, wobei zu bemerken ist, dass Plasmazellen ja gelegentlich auch schon im normalen hämopoëtischen Gewebe gefunden wurden (durch Einwirkung nnoch physiologischer" Reizungen), dass ihre massenhafte Vermehrung aber unbedingt entzündlicher Natur ist.

Ferner sind in einem gewissen Anfangsstadium die entzündlich granulierenden Affektionen durch blossen Rundzellreichtum ohne Fibro-

1) cf. Assmann, Zieglers Beiträge. 1907. Bd. 41.

2) Webb, Dissert. Breslau 1910/1911. 
blastenbeteiligung (Virchows Indifferenzstadjum) von den leukämischen reinen Parenchymaffektionen histologisch nicht zu unterscheiden, wie denn ja auch zurzeit indifferente mesenchymatische Bindegewobszellen (Histiocyten) den echten Imphocyten äusserst ähnlich sehen. Weiter kommen auch bei den leukämischen Affektionen, namentlich den akuten, ähnlich wie bei der Granulomatose, kleine Gewebsnekrosen vor; dazu kommt der klinisch fieberhafte Verlauf, der, ebenso wie den granulierenden und tuberkulösen Prozessen, den leukämischen Affektionen, besonders in den akuten Fällen, eigentümlich ist, wie denn die hier oft bestehende hämorrhagische Diathese und begleitende Anämie auch sonst bei den verschiedensten Vergiftungen und Infektionen in gleicher Weise zur Beobachtung kommt. Sternberg hat in jüngster Zeit sogar direkt die akute Myeloblastenleukämie ihrer leukämischen Spezifizität zu entkleiden versucht. Es handele sich nicht um eine spezifisch infektiöse Form der Leukämie mit septischem Organbefund, sondern direkt um einen einfachen septischen Prozess (Streptokokken), um eine bei geeignetem dispositionellem Gewebsreaktionsvermögen ${ }^{1}$ ) blosso leukämoide Blutreaktion bei einfacher septischer Infektion; und auch schon Hansemann hatte verschiedentlich darauf hingewiesen, dass histopathologisch akute lymphatische Leukämien ein Bild darbieten nicht unähnlich dem mancher Typhusfälle ${ }^{2}$ ).

Dazu kommt, dass die myeloide Metaplasie und Erythroblastik bei myeloleukämischen Affektionen völlig die gleiche ist, wie bei anämisierender Intoxikation und Infektion, und dass bei akuten Leukämien die gleichen Vorgänge der Erythrophagie (Goodall) gefunden wurden, wie bei Typhus und gewissen Blutvergiftungen (Pyrodin, Pyrogallol usw.).

Nicht unwichtig dürfte auch der Umstand sein, dass in neuester Zeit bei histologisch tuberkulosefreien leukämischen Prozessen bacilläre Erreger spärlich, aber von einwandfreien Forschern nachgewiesen sind, namentlich säurefeste Stäbchen von Fränkel-Much, Coley-Ewing, Arndt, ebensowie auch in den echten Lymphosarkomen Kundrats Tuberkelbacillen gefunden sind von Ricker und Claus, und in jüngster Zeit besonders von Brandts ${ }^{3}$ ). Dazu kommt, dass Ellermann-Bang von der Hühnerleukämie berichten, dass ihnen die Uebertragung durch zellfreien Presssaft gelungen sei. Die Behauptung von Friedberger-Burckhardt indes, dass die Hübnerleukämie eine blosse Form der gewöhnlichen Hühnertuberkulose sei, dürfte mit Hirschfeld-Jacoby abzulehnen sein. Es spricht also vieles für die infektiöse Natur und Ursache der Leukämien, zumal, wenn die akuten und chronischen Leukämien zusammengehören. Offen bleibt die Frage, ob spezifische Erreger anzunehmen sind, oder unspezifische Erreger bei geeigneter Disposition des hämopoëtischen Affekts genügen.

Schliesslich besteht noch das Problem der Disposition.

Wie für die Tumorbildung, so wäre auch wohl für die Leukämieerkrankung die spezifische Disposition ein nicht zu vernachlässigendes

1) Sternberg, Wiener klin. Wochenschr.; siehe neuerdings auch PribramStein, Wiener klin. Wochenschr. 1913. Nr. 49.

2) cf. Marcuse, Virchows drchir. Bd. 160.

3) Münchner med. Wochenschr. 1908. Nr. 14. 
Moment. Denn wenn die Erreger der Leukämie nicht spezifisch, sondern septisch, oder in chronischen Formen artverwandt denen der infektiösen Granulome wären, so müsste es erklärt werden, warum in dem einem Fall neben der Parenchymwucherung auch noch stromatische Reaktion eintritt, im andern Fall aber ausbleibt.

Ein sehr merk würdiges Moment, das die Hämatologie intensiv beschäftigt hat, ist ferner bei den Leukämien die strenge Differenzierung im Sinne des Dualismus. Entweder es erkrankt das lymphatische oder aber das myeloide Gewebe. Der früher in der Literatur gemeldete Uebergang myeloischer Formen in lymphocytäre (Wilkinson ${ }^{1}$ ), Malland $\left.{ }^{2}\right), \operatorname{Scott}^{3}$ ), Hirsch $\left.\left(e / d^{4}\right)\right]$ ist von uns ${ }^{5}$ ) als Entdifferenzierung der myeloischen Wucherung in einseitige Lymphoidocytenwucherung, $d$. h. verminderte Umbildung der im Indifferenzzustand stehenbleibenden wuchernden Stammzellen unter zunehmender Akuität des Prozesses oder therapeutischer Massnahmen (Röntgenstrahlen) gedeutet und fast allgemein in diesem Sinne anerkannt worden [Naegeli, Klieneberger ${ }^{6}$ ), Steffler ${ }^{7}$ ), Jagic].

Auch die angeblichen Mischfälle, die Türk, Hirschfeld und besonders A. $\mathrm{Her} \mathrm{z}^{8}$ ) beobachtet haben wollen, konnten bisher von uns noch immer zwanglos als Kombinationen der Hyperplasie des einen Gewebssystems mit blosser irritativer Reaktion des anderen gedeutet worden. So findet man gelegentlich bei Jymphatischer Leukämie myeloide Metaplasie dor Lvmphsinus, und wohl auch umgekehrt bei myeloiseher Hyperplasie rundzellig lymphocytäre Granulation der Milzkapsel.

Es ist diese strenge Elektion und Distribution auf zwei verschiedene Gewebssysteme bisher noch nicht hinreichend erklärt. Soll man annehmen, dass jede Leukämie ihren besonderen Erreger hat? Dann müsste man annehmen, dass der eine Erreger nur auf den einen Apparat, der andere nur auf den anderen abgestimmt ist. Oder soll man annehmen - was uns wahrscheinlicher scheint --, dass ein und derselbe Erreger beide Gewebe in Hyperplasie versetzen kann? Je nach seiner Virulenz oder dem Grade seiner Toxizität würde bald das eine, bald das andere Gewebe in Reaktion versetzt werden, wie denn auch der Tuberkelbazillus oder der Typhuserreger je nach der Reaktionsempfindlichkeit der Gewebe bald an der einen Stelle Eiterung, an der anderen Lymphombildung bezw. Granulombildung hervorruft. Je reizender die Noxe, desto eher reagieren die Zellen des Myeloidgewebes, je abgeschwächter und mitigierter, um so eher die Lymphzellen, deren Reaktionskraft allerdings aber auch viel schwächer und viel weniger imstande ist, die Noxe zu beseitigen oder unschädlich

1) Wilkinson, Lancet 1905.

2) Malland, Lancet 1903.

3) Scott, Lancet 1907.

4) Hirschfold, Berl. klin. Woohenschr. 1907. Fol. haem. VI. 1908. S. 382.

5) Ueber die Stellung der akuten Leukämie usw. Fol. haem. IV. 1907. S. $564 \mathrm{ff}$, 581 ff. Verhandl, d. Deutschen Pathol. Ges. 1907. S. 367; s. a. Zeitschr. f. klin. Med. Bd. 47. S. 261. Bd. 52. S. 276-282.

6) Deutsche med. Wochenschr. 1909. Nr. 49.

7) Steffler, Deutsohes Arch. f. klin. Med. Bd. 106.

8) Herz, Wiener klin. Wochenschr. 1909. 
zu machen. Schliesslich käme noch in Frage, ob die Reaktion des einen oder anderen Apparates nicht bloss davon abhängt, ob der Erreger zufällig lokal mit dem Lymphstrom in den einen oder mit dem Blutstrom in den anderen Apparat gelangt.

Wir möchten vorläufig am meisten zu der zweit erwähnten Möglichkeit hinneigen. Nach dieser würden sich die leukämischen Affektionen im Prinzip ganz so wie sonstige Infektionen verhalten, nur dass die stromatische Reaktion unterdrückt ist, und sie würden mit der Tumorbildung das gemeinsam haben, dass es infolge Fehlens der stromatischen Reaktion zu einer Hyperkompensation, einer luxurierenden Wucherung der reagierenden Parenchymzellen im Sinne von Weigert kommt (cf. Keloidbildung). Das dispositionelle Moment, weshalb eine leukämische hyperplastische Aflektion statt eines blossen entzündlichen metaplastischen Vorgangs erfolgt, läge dann also in der relativen stromatischen Reaktionsschwäche der befallenen Gewebe. Die Parenchymreaktion überwindet die Nesenchymreaktion.

Das wahre und eigentliche direkte ursächliclie Moment, weshalb es bei irgendwelchen subchronischen äusseren Reizen statt zur entzündlichen limitierten Reaktion zur malignen cytotypen Zellwucherung kommt, liegt vermutlich ähnlich in einer internen tumorösen Disposition des Gewebes (Hemmungslähmung).

Die Ursache, weshalb eine lymphatische statt einer myeloischen Affektion erfolgte, könnte dagegen in der graducllen Virulenzdifferenz der externen Noxe zu suchen sein. Fs darf aber nicht unerwähnt bleiben, dass noch eine ganz andere Erklärung für das letztere Verhalien versucht wurde von K. Ziegler ${ }^{1}$, welcher das verschiedene Verhalten des lymphatischen und myeloischen Gowebes gegenüber den Röutgenstrahlen zum Ausgang seiner Theorie nahm. Wir wissen nämlich seit Heineke und Meyer, dass bei Bestrahlung der normalen Milz der Lymphknötchenapparat empfindlicher sein soll als die Pulpa und zur Atrophie gelangt, während umgekehrt die letztere sekundär hierbei zur Wucherung angeregt wird und noch obendrein in myeloider Metaplasie. (Dagegen dürfte bei der myeloiden Leukümie die myeloide Wucherung der Milzpulpa als das Primäre, die Knötchenatrophie als das Sekundäre, bedingt durch Substitution durch jene zu deuten sein.)

Nun ist es Ziegler bei seinen Experimenten mit Röntgenstrahlen fraglos nicht gelungen, eine echte myoloide Leukämie zu erzeugen; er erhielt lediglich banale mononucleäre Leukocytose; er glaubte sich trotzdem hinreichend berechtigt, das Aufreten der einen oder anderen Iseukämieform zu erklären als eine Gewebshyperplasie des einen hämopoctischen Apparates, angeregt oder bedingt allein durch den Ausfall oder dic Unterdrückung des zweiten Gegenapparates; ähnlich wie bei den Drüsen mit interner Sekretion der Funktionsausfall der einen ein störendes Uebergewicht einer anderen antagonistischen Drüse zur Folge hat. Ziegler hat durch Röntgenbestrahlung gewissermassen eine leukämische Disposition zu schaffen geglaubt (direkte Vernichtung des einen Antagonisten und dadurch

1) Histogønese der myøloiden Leukämie. 1906. 
bedingte indirekte leukämische Reizung des anderen); vielleicht wäre es aussichtsvoller, durch chronische Bestrahlung des einen Antagonisten in kleinen blossen Reizdosen zu versuchen, diesen selbst direkt in leukämische Wucherung zu versetzen.

Wie dem auch sei, ob dieser Gedanke sich als fruchtbar erweisen wird oder nicht 1 ), bestehen bleibt als Tatsache ein gewisses antagonistisches Verhältnis des lymphatischen und myeloischen Apparates bei den leukämischen Erkrankungen. Dieses macht sich besonders auch in therapeutischer Hinsicht geltend, insofern als, abweichend ron der Norm, d. h. dem normalen Lymphdrüsenapparate, der leukämisch affizierte lymphatische Apparat dureh die Strahlen schlechter und schwerer $z u$ beeinflussen ist als der myeloisch leukämische Apparat.

Worin dieser Unterschicd des gesunden und erkrankten hämopoetischen Apparates gegenüber den Röntgenstrahlen liegt, jst noch nicht festgestellt. Erwähnt muss aber werden, dass dic Röntgenstrahlen hier bei den leukämischen Erkrankungen, ähnlich wie bei den malignen Tumoren, sich als von zwiefacher Wirksamkeit erweisen. Wie maligne Tumoren durch die Strahlen nicht nur günstig beeinflusst werden. sondern wie umgekehrt bei Applikation auf gesundes aber disponiertes Gewebe die Strahlen bei ungeeigneter Applikation eine maligne Wucherung (Röntgenkrebs) zur Auslösung bringen können, so werden auch myeloleukämische Wucherungen nicht unter allen Unständen günstig beeinflusst, sondern im Gegenteil gelegentlich zur myeloblastischen Entdifferenzierung, d. h. zur Verschlechterung und Unwandlung in einen mindestens histologisch akuteren Vorgang versetzt. Dies beruht darauf, dass das krankhaft leukämisch gewucherte myeloische Gewebe durch die Strahlenwirkung In einen noch gereizteren Zustand (vermehrte Zellwucherung unter behinderter ${ }^{2}$ ) Zellumbildung und Reifung) versetat wird, ohne dass die Ursache zerstört wird. Demgegenüber will Ziegler bei Bestrahlung gesunden Gewebes umgekehrt Leukämie erzeugt. haben, dadurch dass er ein zweites (gesundes) Gewebe ausschaltete. Hier soll also Iseukämie nicht aus dem einen bestrahlten und dadurch gereizten Gewebe entstanden sein,

1) Gegen die Richtigkeit der Zieglerschen Theorie, dass ein blosser vorhandener primärer Leukocytenschwund die ausreichende interne Ursache dafür sei, dass eine Lympholeukämie entsteht, spricht die Tatsache, dass bei Leukämio die Anordnung der histologischen Leukomeruptionen an Verteilung der Lokalisation eine von Fall zu Fall wechselnde ist, während die Theorie Zieglers verlangen würde, dass allenthalben das gesamte lymphadenoide Gewebssystem in vicariierende Hyperplasie gerät.

Das tatsächliche wechselvolle Verbalten spricht vielmehr in unserem oben ausgeführten Sinne für die Annahme noch eines exogen ursächlichen, infektiös entzündlich-leukämischen Reizes neben einer internen Prädisposition, dessen jeweilige lokale Etablierung die verschiedene Anordnung der Leukomeruptionen bedingt. Auch wenn sich die Existenz gemischter Leukämiefälle bestätigen sollte (neuerdings Herx h ei m $\theta$ r, Münchener med. Wochenschr. 1913. Nr. 45/46), so wïrde das gegen die Richtigheit. der Zieglersche Theorie sprechen.

2) Die Reifungsumbildung kann behindert sein durch die Acuität der Wucherung solbst (Pappenbeim) als durch die Strahlenwirkung (Jagic). 
wie das Röntgencancroid aus den bestrahlten Epithelzellen, sondern aus dem nicht direkt auf die Strahlen reagierenden, vielmehr blos durch den Ausfall der lymphoiden Komponente die Ueberhand gewinnenden myeloiden Pulpagewebe, während die bestrahlten Lymphknotenzellen unter der $\mathrm{Be}-$ strahlung zugrunde gingen.

Wie es in der Lehre von den Infektionskrankheiten und ihrer Bekämpfung als gesicherte Tatsache gelten kann, dass dieselbe Ursache, welche die Krankheit auslöst, bei abgeschwächter Virulenz einen kurativen Einfluss auf die Krankheit ausübt, nicht durch Einwirkung auf die pathogene Ursache und ihre Krankheitsprodukte, sondern durch Stimulation der Abwehrkräfte des Organismus (aktive Immunisierung), ebenso wird auch in der Lehre von den Tumoren und ganz besonders von den leukämischen Affektionen die Heilung einmal von der Kenntnis der Ursache selbst abhängig werden. Jedenfalls tritt bei der Erzeugung und Unterdrückung von Tumoren und leukämischen Affektionen durch dasselbe Agens ${ }^{1}$ ), die Strahlen, ein bei beiden gleiches Prinzip zu Tage. Es ist daher sehr wohl möglich, dass eine rationelle Therapio all dieser furchtbaren Krankheiten nicht eher wird geschaffen werden können, bis ihre Aetiologie völlig aufgeklärt sein wird.

Dass man hinsichtlich der Aufklärung der leukämischen Aetiologie noch ganz in den Anfangsstadien steckt, haben wir schon erwähnt. Alle Versuche, auf experimentellem Wege künstlich leukämie zu erzeugen, sind bisher fehlgeschlagen. Durch infektiöse Eitererreger konnte man bisher nur Leukocytosen, durch Granulationserreger in besten Fall Lymphocytosen erzielen. Dass auf eine besondere individuelle Disposition des Versuchstieres und Virulenzabstufung der Noxe Rücksicht genommen werden musste, wurde bisher bei den diesbezüglichen Versuchsanordnungen nicht beachtet.

Was chemische Mittel anbetrifft, so gelang es bisher durch Nucleinsäure auch nur Leukocytose, durch Tuberkulin und Pilokarpin bestenfalls Lymphocytose zu erzeugen. Sehr beachtenswert sind dagegen die Resultate, die Kasarinof $f^{2}$ ) (unter meiner Leitung) bei Vögeln unter kombinierter Verwendung zweier Blutgifte, des Ricins und Saponins erhalten hal, deren eines eine dispositionelle Schwächung setzte, das andere dann eine nicht gewöhnliche zur leukämoiden Blutveränderung fïhrende Reizung des hämopoëtischen Apparates ausüben konnte.

So lange die Vergiftung anhielt, kam es zu einem so massenhaften Uebertritt von Leukocyten und zwar völlig unreifer Knochenmarkselemente ins Blut, dass ein von gewöhnlicher Leukocytose völlig rerschiedener Aspekt sich darbot. Es ist zu beachten, dass diese Blutgifte, speziell das Saponin, bei Einverleibung in den Körper weniger erythrolytisch auf die cursierenden Blutkörperchen als stimulierend (Leukocytose, Erythroblastose) auf die Zellen des blutbildenden Apparates einwirken (Isaak, Pappenheim-Szecsi).

1) Leukämie日rzeugung durch Strahlen (Ziegler) und Unterdrückung (Senn); Tumorerzeugung durch Strablen (Röntgencarcinom) und Unterdrückung.

2) Folia. haematol. Bd. X. 1909. 
Es ist ferner zu beachten, dass diese Blutgifte alle Lipoidlöser sind, gerade dadurch, wegen ihrer lipolytischen Eähigkeit, zu Blutgiften werden, und dass daher alle Blutgifte auch Nervengifte, (vielfach auch hämorrhagische Endothelgifte) sind. (Streptolysin, Tetanolysin, Schlangengifte, Gift der perniziösen Anämie.)

A priori dürfte aus Analogieschlüssen wahrscheinlich sein, dass das Leukämietoxin, welches ja vielfach auch noch eine anämisierende und erythrohyperplastische Komponente hat (sogen. Leukanämie) und in akuten Fällen Hämorrhagien macht, ebenfalls ein Hämolyticum lipoidlöslicher Natur ist.

2. Wenden wir uns von den Berichten über die erfolglose Erforschung der leukämischen Aetiologie zur Therapie, so ist das frülier beliebte Arsen hier in letzter Zeit fast völlig verdrängt worden, seitdem Senn im Jahre 1904 die eminente Wirkung der Röntgenstrahlen festgestellt hat. Dass der lymphatische Apparat hier weniger reagiert, wie der myeloische, ist schon erwähnt. Komplette Heilungen sind aber auch bei den myeloischen Heilungen nio erzielt worden, da es sich vermutlich nur um symptomatische Beeinflussung der Zellwucherung, nicht um Beseitigung der internen Disposition und der äusseren ursächlichen Noxe handelt. Das Blut der Kranken indes wird bei der Bestrahlung durch direkte Zerstörung der cursierenden leukocyten und Störung der Zellbildung in den hämocytoblastischen Organen während der Dauer der Strahlennachwirkung leukopenisch.

Die Röntgenstrahlen wurden abgelöst durch das Radium und neuerdings durch andere radioactive Elemente wie Mesothorium und Thorium X. Besonders das letztere hat eine auffällige eklatante und sehr drastische Wirksamkeit gegenüber der Myeloleukämie, wie in übereinstimmender Weise Plesch, Falta und Gudzent dargetan haben. Allerdings sind Dauerheilungen auch hier bisher nicht beobachtet worden, wohl aber öfters viel grössere Intermissionen aleukämischen Blutzustandes als bei Radium- und Röntgenstrahlen.

Verfasser hat hier [gemeinsam mit Plesch $\left.{ }^{1}\right)$ ] festgestellt, dass beim gesunden Organismus die therapoutische Partialcomponente in einer direkten Zerstörung der Blutzellen im Blut vor allem der Leukocyten, aber auch der Lymphocyten, ferner in einer completen Zerstörung der Myeloidgewebszellen im Knochenmark nebst einer Fibroblastengranulation in den Lymphknoten beruht, durch welch letztere die Lymphocyten bloss zur Rarefication, nicht zum völligen Schwund gebracht werden. Dagegen hat das Thorium bei Application in zu hohen Dosen allerdings auch noch eine unerwünschte Nebenwirkung im Auftreten von hämorrhagischer Diathese und Leberparenchymschädigung (centrale Nekrosen und Nekrobiosen), welche Pappenheim und Plesch ebenso wie $\mathrm{Löhe}^{2}$ ) feststellen konnten. Bei müssig grossen therapeutischen Dosen ( $1-3$ Millionen M. E.) kommt vor allem die zellzerstörende antileukämische Wirkung zur Geltung, indes ist die un-

1) Pappenheim und Plesch, Folia haematol. Archiv. 1912. Bd. 14, und Diese Zeitschr. 1912. Bd. 12.

2) Löhe, Virchows Archiv. Bd. 209. 
erwünschte nekrotisierende und hämorrhagische Wirkung stets zu fürchten, denn die Dosis efficax liegt nicht weit entfernt unterhalb der Dosis letalis.

In kleinen Dosen 30000-50000 M.E. (Reizdosen) wirkt das Thorium X auffallend günstig bei perniziöser Anämie, was dafür spricht, dass bei dieser Krankheit dem Knochenmark vielleicht doch nicht nur eine bloss regenerative Reaction zufällt. (Bei Röntgenstrahlen will Mosse allerdings früher seitens der Erythrocyten ein völlig refractäres Verhalten gegenüber dieser Strahlenart beobachtet haben.)

Dass Radium in kleinen Dosen deutliche starke lymphämieähnliche Lymphocytose nach Gudzent-Lewy hervorrufen soll, sei nur nebenbei erwähnt. Es ist das ein ähnlicher elektiver Reiz auf das eine System, wie wir ihn oben von den Röntgenstrahlen berichtet haben.

Man kann hier annehmen, dass die Strahlen in ganz schwacher Dosierung auf eine bestimmte Zellart (Lymphocyten) anregend wirken und dadurch die Lymphocyten zur Vermehrung bringen, in stärkerer Dosierung aber dieselben Iymphocyten zerstören, wodurch dann indirekt die Leukocyten zur Vermehrung gelangen würden (um bei noch stärkerer Dosis ebenfalls zerstört zu werden), dass also die Strahlen auch nur auf eine Zellart, die Lymphoeyten, spezifisch irritierend oder paralytisch wirken. Oder es wäre möglich, dass die Strahlen in schwacher Dosis auf die eine Zellart, die Lymphocyten, in stärkerer, auf die andere Zellart, die Leukocyten, anregend wirken; oder schliesslich, dass schon die primäre Jymphocytose garnicht durch aktinische Reizung der Lymphocyten selbst zustande kommt, sondern eine Folge vorangehender Zerstörung der empfindlicheren Myeloidzellen ist. Bei stärkerer Reizapplikation würden aber dann nach der einen wie nach der anderen Auffassung auch die Lymphocyten zerstört. Die Strahlen würden also auf zweierlei Zellen zerstörend wirken, auf die eine Zellart in schwacher, auf die andere in starker Dosis.

Diese zweite vorgetragene $\Lambda$ uffassung, nach der das Vyeloidsystem schon durch schwächere Strahlendosen als das Lymphadenoidsystem zerstört wird, würde allerdings im Widerspruch stehen zu den Deutungen, die Meyer-Heineke und Ziegler ihren Beobachtungen gegeben haben. Nach diesen Autoren würden die lymphocyten die empfindlichere Zcllart gegenüber den Röntgenstrahlen sein.

Demgegenüber haben indes meine zusammen mit Plesch unternommenen Beobachtungen der Thorium X-Wirkung Resultate ergeben, welche nicht ganz mit den bei Röntgenisierung erhobenen Befunden von Meyer-Heineke und Ziegler harmonieren. Wir fanden nämlich, dass die Myeloidzellen die empfindlicheren sind und eher zerstört werden, als das Lymphadenoidgewebe. Mit dieser grösseren Empfindlichkeit des Myeloidgewebes harmoniert auch unter pathologischen Zuständen das leichtere Reagieren der Myeloleukämien auf mittlere Heildosen gegenüber den Lympholeukämien.

Im Sinne von Ziegler und Meyer-Heineke müsste man eine biologische Differenz zwischen normalen und leukämischen Lymphocyten annehmen, so'zwar, dass die normalen gegen die Strahlendosen sehr empfindlich, die leukämischen sehr resistent sind, für welchen inhomo- 
genen Dualismus bisher alle sontigen Unterlagen fehlen. Das ist eben schwer vorstellbar.

Wir werden uns an der Hand eigener Versuche, über die wir weiterhin berichten wollen, überzeugen, ob wir zu denselben Resultaten wie Ziegler gelangen, und welcher Annahme die histologischen Grundlagen entsprechen.

Die neueste Phase in der Behandlung der Leukämien wird durch das von Koranyi zu diesem Zweck inaugurierte Benzol repräsentiert.

Nach Koranyi soll Erfolg bei allen Formen myeloischer Leukämie eintreten. Die lymphatische Form scheint weniger beeinflussbar. Benzol soll Erfolg auch da haben, wo die Röntgentherapie versagt. Kleine Dosen scheinen die Leukopoese anzuregen, deshalb sind grosse Dosen (3-4 $\mathrm{g}$ pro die) monatelang angezeigt. Unangenehme Nobenwirkungen wurden nicht beobachtet. Die Empfehlung Koranyis stütat sich auf zwei Punkte; einmal sind vom Thorium bei unvorsichtiger Applikation unerwünschte Nebenwirkungen beobachtet worden, ferner ist die intravenöse Applikation des Thorium immerhin ein gewisser Eingriff, den man bei der internen (peroralen oder peranalen) Darreichung des Benzols nicht nötig hat.

Die Röntgenbehandlung ist ebenfalls mit ihren wiederholten Sessionen umständlich, und es ist garnicht zu leugnen, dass es ein idealer Fortschritt wäre, wenn wir ein Mittel hätten, das bei interner Darreichung alle Vorzüge der umständlichen Röntgenbestrahlung oder der intravenösen Thoriumapplikation besässe, ohne deren Schattenseiten.

Der wichtigste und massgebliche Gesichtspunkt aber, der Koranyi veranlasste, das Benzol als Antileukämicum zu verwenden, knüpft an experimentelle Untersuchungen an, die Selling ${ }^{1}$ ) vor einiger Zeit bekannt gegeben hat. Wir wollen über die Ergebnisse Sellings im folgenden kurz berichten.

Angeregt durch 3 Fälle von menschlicher Benzolvergiftung, die alle mit Leukopenie des Blutes einhergingen, studierte Selling die Wirkung desselben auf den hämopoetischen Apparat bei Kaninchen, indem er Benzol mit Olivenöl zu gleichen Teilen täglich subcutan injizierte in Mengen von $1 \mathrm{ccm}$ Benzol pro Kilogramm Körpergewicht.

Das Resultat seiner Versuche ist kurz folgendes: Benzol wirkt in schwachen Dosen die Zelldifferenzierung anregend, in stärkeren zerstörend auf die weissen Blutkörperchen im circulierenden Blut und die Parenchymzellen der hämopoetischen Organe. Das myeloide Gewebe wird stärker als das lymphadenoide Gewebe getroffen. Wiederholte Benzolinjektionen können vollkommene Aplasie des lymphadenoiden und myeloiden Gewebes bedingen. 3-4 Tage nach der letzten Injektion treten selbst nach vollkommener Aplasie regenerative Veränderungen wieder auf, die die Regeneration innerhalb 10 Tagen bis 3 Monaten zu einer vollständigen machen. Am widerstandsfähigsten gegen das Gift erweisen sich die kleinen Lymphocyten; es folgen in absteigender Linie Erythroblasten, Riesenzellen, grosse Lymphocyten, Myelocyten und polynucleäre

1) Benzol als Leukotoxin. Zieglers Beitr. Bd. 51. 1911. 
Granulocyten. In der Mlilz werden Ncubildungen von myeloiden Zellelementen beobachtec. Ueber Veränderungen an anderen Organen berichtet Selling nichts.

Es lässt sich nicht leugnen, dass die von Selling bekannt gegebenen Beobachtungen in der 'Tat geeignet scheinen, zu einem Versuch der therapeutischen Beeinflussung von Leukämien und anderen Erkrankungen des hämopoetischen Apparates anzuregen. In der Tat zeigen sie auch sonst grosse Achnlichkeiten nicht so sehr mit der Röntgen- und Radiumwirkung, als besonders mit der von uns und Plesch gefundenen Thoriumwirkung auf den hämopoetischen Apparat. Anch beim Thorium hatten wir die gleiche Zerstörung der Parenchymzellen des hämopoetischen Apparates and die bis zur totalen Leukopenie und Entvölkerung von Leukocyten führende Einwirkung aul das circulierende Blut. Auch beim Thorium hatten wir ganz die gleiche graduelle Differenz der Empfindlichkeit $z$ wischen Jymphadenoidem und myeloidem Gewebssystem. Während aber wir bei unseren Versuchen mit Thorium als unerwünschte Nebenwirkungen auch noch colossale Blutdrucksenkung, verbunden mit ausgedehnten Blutungen und Nekrosen, bei den Dosen erhielten, die eine völlige Zerstörung des Knochenmarks nach sich zogen - Dosen, wie sie im Verhältnis natürlich bei der therapeutischen antileukämischen Verabfolgung, und erst recht bei der antianämischen Reiztherapie, niemals zur Verwendung kommen - berichtet Selling in seinen bezüglichen Versuchen, dio sich nur auf den hämopoetischen Apparat beschränkten, nichts über derartige Nebenerscheinungen.

Bevor aber der gewissenhafte Kliniker ein solches einschneidendes und drastisches Mittel beim Menschen versucht, sollte er natürlich nach jeder Richtung hin seine toxikologischen und pharmakodynamischen Potenzen eingehendst kennen und beherrschen.

Ich begrüsste es daher mit lebhafter Genugtuung, als mir Herr Geh. Rat Kraus den Auftrag erteilte, nochmals selbständige Versucho über die Benzolwirkung, nicht nur auf den hämopoetischen Apparat im besonderen, sondern auch auf die sonstigen Organe anzustellen, um so ein Urteil über seine Verwendungsfähigkeit in der humanen Therapie, das Prinzip seiner Wirkung, seine Unterschiede gegenüber dem Thorium und etwaige Nebenwirkungen zu gewinnen.

A priori ist es ja wohl nicht unwahrscheinlich, dass ein so stark feitlösender Körper wie das Benzol Nebenwirkungen besonders auf das Nervensystem wird haben können.

Auch Selling führt aus der Vergiftungsliteratur gewisse vorübergehende Einwirkungen auf den hämopoetischen Apparat und Veränderungen des Blutes an. So erwähnt er, dass Santesson ${ }^{1}$ ) in einem Vergiftungsfalle Leukopenie, Ianglois-Desbouis? ${ }^{2}$ ) in ihrem Fallo Hyperglobulie beobachtet haben. Demgegenüber berichtet $\mathrm{L}$. J e w in in seinem Lehrbuch der Toxikologie, dass beim Menschen Einatmung von Benzoldämpfen (in Gummifabriken) jahrelang ohne jegliche Benachteili-

1) Arch. f. Hygiene. Bd. 21. 1897.

2) Journal de physiologie et de pathologie générale. IX. 1901. 
gung der Gesundheit vertragen wird; dass vom Magen aus $2-3 \mathrm{~g}$, ja selbst $8 \mathrm{~g}$ vertragen werden, dass aber bei Idiosynkrasien oder bei versehentlich zu grossen Dosen Benommenheit, schwankender Gang und sogar Delirien beobachtet wurden.

Sommerfeld und Fischer geben in ihrer Liste der gewerblichen Gifte an, dass das Benzol eine spezifische Affinität zum Centralnervensystem und eine Allgemeinwirkung auf das Zellprotoplasma (fettige Degeneration) zeigt. Bei subacuten und chronischen Vergiftungen treten starke Anämie, Schleimhaut- (Uterus) und Hautblutungen auf, neben fettiger Degeneration von Herz, Leber und Niere. Bei acuten Vergiftungen findet sich ein rauschähnlicher Zustand mit Schläfrigkeit, Schwindelgefühl und Euphorie in den leichteren Fällen. In den schwereren Fällen frostschauerähnliches Zittern, Muskelzuckungen, tonische und klonische Krämpfe. Hier wird also jedenfalls des Benzols als eines hämorrhagischen und Nervengifts und einer anämisierenden Noxe gedacht, wie denn ja überhaupt bei den Blutkrankheiten diese 3 (lipolytischen) Componenten, die anämisierende (mit der leukocytotischen), die neurotoxische und die hämorrhagisch-endotheliotoxische (und globulinolytische, Gerinnung hemmende) vielfach miteinander kombiniert vorkommen.

Ich erinnere an die hämorrhagische Diathese bei akuter Leukämie und bei septisch-leukocytotischen Prozessen, an die die Leukämie begleitende anämische Componente bei Leukanämie, an die Störungen des Centralnervensystems und die verzögerte Gerinnung bei perniciöser Anämie und ihre Retinalblutungen, an die neurotoxischen Wirkungen der anämisierenden Gifte, wie Pyrodin, Saponin, Hydroxylamin, Schlangengift. Vor allem aber scheint mir hier besonders hervorgehoben werden zu müssen, dass ein neuerer amerikanischer Forscher Duke ${ }^{1}$ ) das Benzol direkt neben dem Diphtherietoxin als ein Gift anführt, welches spezifisch hämorrhagisch und gerinnungsverzögernd wirkt.

\section{Eigene Versache.}

Nach diesen Vorausschickungen will ich nun über das Ergebnis meiner eigenen Versuche berichten. Unter dem Einfluss der Voreingenommenheit, dass Benzol, dieser stark fettlösende Körper von hohem spezifischen Gewicht, nach den bisher in der toxikologischen Literatur niedergelegten spärlichen Mitteilungen, ein keineswegs ganz gleichgültiger Körper sein dürfte, interessierte es mich, zu wissen, welchen Einfluss auf die Leukocyten und den bämopoetisehen Apparat wohl auch noch andere ähnliche fettlösende Körper haben möchten, speziell das Benzin oder der Petroläther, der ja zu einer ganz anderen Kohlenwasserstoffgruppe, nämlich den aliphatischen Körpern gehört, und meist ein Gemisch von Hexan und Pentan ist, zudem ein ausserordentlich geringes spezifisches Gewicht hat. In bezug auf Fettlöslichkeit und spezifisches Gewicht verhalten sich etwa Benzol und Benzin zueinander wohl ähnlich, wie die beiden Narkotica Chloroform und Aether. Vielleicht dass also auch das Benzin den gleichen gewünschten Erfolg bei geringerer Nebenschädlichkeit haben müchte.

1) Duke, John Hopkins Bullet. 1912. XXIII. Nr. 255. S. 144. 
Um imstande zu sein, die Wirkung des Benzols und die etwaige des Benzins auf den hämopoetischen Apparat beurteilen und bewerten zu können, habe ich auch noch eine Versuchsreihe mit Röntgenisierang, und zwar im Tierversuch wohl zum ersten Male mit genau nach Erythem-Dosen dosierten Strahlungen vorgenommen.

\section{Plan der Arbeit.}

1. Wir werden im folgenden also das Prinzip der Benzinwirkung auf den hämopoetischen Apparat und etwaige Folgeerscheinungen an sonstigen Körpergeweben an einer Versuchsreihe mit mittelgrossen und grossen Benzindosen $(4-8 \mathrm{ccm})$ zu ergründen suchen.

2. Ebenso werden wir an einer zweiten Versuchsreihe die entsprechenden Versuche auch mit Benzol vornehmen und dieselben mit den von Selling gefundenen Resultaten zu vergleichen haben.

3. Wir werden drittens alsdann die beiderseitige Wirkung miteinander vergleichen.

4. Das Ergebnis der Röntgenstrahlen und der Thoriuminjektionen auf den hämopoetischen Apparat ist durch die Arbeiten von Heineke und Pappenheim-Plesch bereits hinlänglich festgelegt worden. Die Protokolle unserer Thoriumversuche sind jüngst in extenso ${ }^{1}$ ) publiziert worden; die mikroskopischen Präparate stehen uns zum Vergleich zudem noch zur Verfügung.

5. Eine besondere Versuchreihe mit Röntgenbestrahlung haben aber auch wir von neuem ausdrücklich zu dem Zweck unternommen, um deren Ergebnisse mit der Thoriumwirkung zu eigenem Urteil vergleichen zu können, und um dann das Ergebnis der Benzol- und Benzinversuche mit dem der Röntgen- und Thoriumversuche in Beziehung setzen zu können.

Alle diese Versuche und Feststellungen wurden aussschliesslich am Kaninchen erhoben.

A.

Aus unseren im grösseren Massstabe vorgenommenen Thorinmversuchen sei kurz das Ergebnis rekapituliert.

Nach einer einmaligen intravenös verabfolgten Dose von mindestens 5 M.-E. war um den dritten Tag herum das Blut vollständig leukocytenfrei. Die Lymphocyten waren zuerst verschwunden.

Um den vierten Tag herum starben die Tiere spontan.

Das Knochenmark war dunkel himbeergeleerot, dünnflüssig und aus der Knochenkapsel herausfliessend.

Die Milz war atrophisch und tief dunkel gefärbt.

Mikroskopisch fand sich enormer Blutreichtum sämtlicher Organe durch Gefässerweiterung und Wanderschlaffung, vielfach verbunden mit Blutungen per rhexin.

In der Leber fanden sich bald diffuser nekrobiotischer Zellverfall mit fettiger Entmischung, bald centrale Druckatrophien durch Stauung, bald direkte centrale Nekrosen.

1) Diese Zeitschr. Bd. 12. 
In der Niere Cylinder in den Harnkanälchen und Exsudat im Bowmanschen Kapselraum.

Im Knochenmark totaler Verlust des Zellparenchyms mit Blutinfarcierung der Fetträume. Und zwar schwinden dabei die hochdifferenzierten Granulocyten zuerst, die tiefstehenden Lymphoidzellen zuletzt.

In der Mil\% ausser Blutanschoppung und Blutungen hochgradigste Atrophie der Follikel mit Rarefikation der Lymphocyten, Erythrocytenzerfall und Erythrophagismus in der Milzpulpa.

B.

Wir werden jetzt zunächst über die von uns erhobenen Ergebnisse der Röntgeneinwirkung auf das Blut und den hämopoetischen Apparat berichten.

Wir verabfolgten eine isolierte Bestrahlung der Milz nach Abdeckung des übrigen Körpers und untersuchten das Blut bzw. die Organe nach Verabfolgung einer auf einmal applicierten oder auf mehrere Tage verteilten grösseren Menge von Erythem-Dosen. Wir verabfolgten die Bestrablung in sehr starker genau dosierter Strahlenmenge, wie das bisher bei experimentellen Röntgenverfahren an Tieren noch nicht so exakt vorgenommen zu sein scheint. (Ziegler gibt in seiner Monographie nur an: ${ }_{n}$ Die Kaninchen wurden teils kürzere, teils längere Zeit bestrahlt ${ }^{4}$.)

Wir verabfolgten mit mittelharten Röbren eine hohe Anzah! ron Erythem-Dosen, meist in einer Sitzung, gelegentlich fraktioniert. Ziegler bestrahlte ein- bis zweimal und beobachtete dann die Tiere wochenlang, bevor er sie tötete. Nach unseren sehr intensiven Bestrahlungen gingen die Tiere sämtlich unter starker Abmagerung spontan ein.

\section{Vorbemerkung.}

Das Blut des gesunden Kaninchens enthält nach unseren Erfahrungen, die mit denen von Ziegler, Klieneberger-Carli ${ }^{1}$ ) und Selling im ganzen übereinstimmen, Kote etwa 4500000-7000000, Leukocyten 6-12000. Da nach Klieneberger-Carl ${ }^{1}$ ) die Tiere dauernd in der Verdauung befindlich sind, ist die Tageszeit der Untersuchung für die Zählung irrelevant.

Die normale Leukocytenformel zeigt durchschnittlich polynucleäre Spezialzellen 35 pCt., Iymphozyten 55 pCt., Monocyten 5 pCt., Mastzellen 4 pCt., Eosinophile 1 pCt.

Ziegle ${ }^{2}$ ) hat bei seinen entsprechenden Versuchen Abnahme der Leukocytenzahl unter 2400 nicht beobachtet (Fall 5), eine $\Lambda$ bnahme der Lymphocyten aber bis auf 1 pCt. (Fall 4). Er fand ferner eine $\Lambda$ trophie mit Zellschwund des gesamten Iymphzellapparates, daneben aber myeloide Metaplasie der Milzpulpa durch Einlagerung der grossen Monocyten des Blutes, die er gamäss seiner eigenartigen, nicht allgemein geteilter Auffassung als verschleppte und aus dem Knochenmark staminende

1) Klieneberger-Carl, Centralbl. f. innere Medizin. 1910.

2) Experimentelle Untersuchungen über die Histogenese der myeloiden Leukämie.

1906. (Gustav Fischer). 
ungekörnte Myelocyten, i. e. Myeloblasten, auffasst. Die lymphoiden Zellen sollen dann in der Pulpa granuliert werden. Ganz im Gegensatz $\mathrm{zu}$ Heineke hat er, entsprechend seiner hierauf ja eben concipierten Leukämietheorie, keine Zellabnahme im Knochenmark wahrgenommen, vielmehr ein wechselnd zellreiches Mark. Soll ja doch gerade durch die Atrophie der Lymphknötchen nach ihm myeloide Hyperplasie erst ausgelöst werden.

Demgegenüber fand Heineke ${ }^{1}$ ) bei seinen klassischen Versuchen als Folge der Bestrahlung eine Abnahme der eirculierenden Leukocyten bis auf 1000, wobei besonders und in erster Linie ebenfalls die Lymphocyten beteiligt sind. Das sonstige qualitative Bild bleibt ziemlich unverändert. Auch er fand eine Atrophie des Lymphadenoidgewebes, speziell kleine pigmenthaltige Milz, aber auch eine Rarefizierung der farblosen Parenchymzellen des Knochenmarks, und zwar eine stärkere der Lymphoidzellen als der Granulocyten, während wir bei Thorium gerade das Umgekehrte gefunden haben.

Folgendes sind unsere Befunde bei Röntgenisierung:

\section{Blutbefunde.}

1. Buntes Kaninchen. Blut im normalen Zustand ohne Besonderbeiten. Rote 5200000 , Leukocyten 10200 .

Blutbefund 1 Tag nach Verabfolgung von 8 Erythem-Dosen (18. 11. 1911): Rote Blutkörperchen obne Besonderheiten. Blutplättchen reichlich vorhanden. Leukocyten Gesamtzahl 6100. Es besteht deutliche relative Prävalenz der polynucleären Spezialzellen ( $90 \mathrm{pCt}$.) mit leichter Verschiebung nach links (Metamyelocyten und vereinzelte Myelocyten). Mastzellen mässig reichlich vorbanden. Grosse Mononucleäre sebr spärlich. Lymphocyton fehlen so gut wie vollständig, desgl. echte Eosinophile. 5 Tage nach der Bestrahlung (23. 11.) beträgt die absolute Lenkocytenzahl 4900.

Nach weiteren 10 Erythem-Dosen zeigen die Roten am folgenden Tage deutliche mikrocytäre Anisocytose. Lymphocyten und Monocyten fehlen, desgl. Eosinophile. Mastzellen sehr spärlich. Die polynucleären Spezialzellen zeigen unreife Vorstufen und Jugendformen mit basophilem Plasma und plumpem Kern. Vereinzelte Reizungszellen, vereinzelte Lymphoidocyten. Exitus des stark dekrepiden Tieres am folgenden Tage.

Bei der Autopsie erscheint das Knochenmark rot, die Milz dunkel. An Leber, Nieren, Lungen makroskopisch nichts Abnormes.

2. Schwarzes Kaninchen. Das Blut zeigt im normalen Zustand keine Besonderheiten. Leukocytenzahl 12500 .

Blutbefund 1 Tag nach 8 Erythem-Dosen (18. 11. 1911): Rote Blutkörperchen ohne Veränderungen. An den Plättohen nichts Besonderes. Leukocyten Gesamtzahl 5900. Es besteht deutliche relative Vermehrung der polynucleären Spezialzellen. Dio Mastzellen in etwa normalem Verhältnis ( $4 \mathrm{pCt}$.) vorhanden. Auch hier fehlen Eosinophile vollständig. Lymphocyten fehlendesgl. fast vollständig!! Die Monocyten sind ausserordentlich spärlich vorhanden. Es finden sich ganz vereinzelte plasmacelluläre Reizungszellen.

Blutbefund nach 8 weiteren Erythem-Dosen: (5 Tage nach der ersten Bestrahlung 23. 11.) Leukocytenzahl 2400. Die polynucleären Leukocyten sind im ganzen leicht vermindert. Lymphocyten und Monocyten fehlen fast röllig. Desgl.

1) Mitteil. a. d. Grenzgebieten. 1905. Bd. 14. Deutsche Zeitschr. f. Chirurgie. 1905. Bd. 78. 
fehlen fast völlig die Eosinophilen. Neben den Spezialzellen finden sich noch etliche Mastzellen. Von pathologischen Zellformen finden sich ausser vereinzelten Reizungsplasmazellen einige wenige Myelocyten und Promyelocyten.

Das Tier ist stark abgemagert und stirbt in der folgenden Nacht. Bei der Autopsie verhalten sich die Organe makroskopisch wie beim vorigen Tier.

3. Graues Kaninoben. Leukocytenzahl 13000. Normale Relationen. 6 Erythem-Dosen in 2 fraktionierten durch 2 Tage getrennten Sitzungen auf die rasierte Milzgegend (letzte am 30. 11.). In dieser Zeit starke Gewichtsabnahme,

Blatbefund am 2. Tag nach der letzten Bestrahlung (2. 11.): Leukocyten 7000. Die Lymphocyten sind ausserordentlich spärlich. Mastzellon und Eosinophile fehlen. Es finden sich ziemlich zahlreiche Plasmareizungszellen und grosse Lymphoidzellen (pathologische Monocyten) von leukoblastischem Habitus. Das Tier orbält boute weitere 2 Erythem-Dosen (2. 12.).

Blutbefund am folgenden Tage (3. 12.): Die Leukocyton (4800) sind auch mikroskopisch nur noch sebr spärlich. Die Spezialzellen zeigen keine Besonderheiten, speziell keine unreifon Formen. Mastzellen und besonders Lymphocyten ausserordentlich spärlich. Eosinophile feblen vollständig. Am zablreichsten findet man grosse atypische Mononucleäre von leukoblastischem Habitus. Das Tier erhält $1,5 \mathrm{ccm}$ einer 2 proz. Lösung von Natron nucleinicum.

Blutbofund am folgenden Tage (4. 12.): Die Blutzusammensetzung ist qualitatir die gleiche wie gestern. Keine mikroskopisoh wahrnehmbare Hyperleukocytose. Leukocytenzahl 5000. Auch keine Zunahme der relativen Vermehrung der polynucleären Spezialzellen. Lymphocyten noch immer sehr spärlich vorhanden. Der einzige Unterschiod gegen gestern und der einzige Reiz, den die Nucleinsäure bat ausüben können, besteht darin, dass die grossen Lymphoidzellen und die polynucleären Spezialzellen höhere Kernfragmentierungen aufweisen.

Blutbefund am folgenden Tage (5. 12.): Die Qualität des mikroskopischen Blutbildes ist die gleiche geblieben, die absolute Zellzahl hat weiter abgenommen: 2800. Jugendformen der Spezialzellen sind nicht aufgetreten, dagegeñ hat ihr Prozentverbältnis gegenüber den anderen Zellen zugenommen. Desgl. die Zahl der grossen leukoblastischen Monocyten und auch der Mastzellen. Eosinophile fehlen. Desgl. Lymphocyten nur in ganz vereinzelten Exemplaren vorhanden, also auf ein Minimum reduziert. Nochmalige Einspritzung von $1 \mathrm{ccm}$ einer 3 proz. Lösung von Natrium nucleinicum.

Blutbefund am folgenden Tage $(6,12$.$) : Die Gesamtzahl der Leukocyten ist$ nicht vermehrt, vielmehr weiter verringert. (1900.) Allein die grossen lymphoiden Zellen sind relativ stärker vermehrt. Lymphocyten fehlen vollständig. Das Tier ist ausserordentlich stark abgemagert. Exitus am selben Tage. Bei der Nekropsienichts Besonderes.

Besprechung. Am Blut zeigen unsere Versuche mit den gewählten starken und genau dosierten Röntgendosen, unter denen die Tiere konstant stark abmagern und, im Gegensatz zu Zieglers Tieren, nach einigen Tagen spontan zu Tode kommen, dass abweichend vom Thorium, von einer vollständigen Leukocytenentvölkerung des Blutes hier nicht die Rede war. Obwohl also die Leukocytenverarmung nicht so weit ging als beim Thorium, sind die Tiere trotzdem äusserst erschöpft. Nucleinsüureinjektion vermag keine Leukocytose mehr zu erzielen. Bei Ziegler gingen in seinen 5 Kaninchenversuchen die Leukocyten nicht unter 2400 herunter (Kan. V). Bei uns wurden einmal 1900 Leukocyten erreicht.

Am stärksten betroffen im Blut und zuerst verschwunden fanden wir die Lymphocyten, was in Uebereinstimmung steht mit unseren beim 
Thorium erhobenen Feststellungen, sowie den Feststellungen von Heineke und Ziegler, nach denen unter Röntgenbestrahlung speziell die Lymphocyten fast völlig aus dem Blut schwinden, während Polynucleäre und Monocyten nach Heineke kaum betroffen sein sollen. Auch nach Ziegler verschwinden die Lymphocyten bis auf wenige Prozent, während die Gesamtzahl der weissen Zellen dem Lymphocytenabfall entsprechend abnimmt. Auch beim Thorium sahen wir zuerst aus dem normalen Blut die Lymphocyten und zwar hier völlig schwinden (während sich das normale und noch mehr das leukämische Lymphadenoidgewebe bekanntlich stets viel resistenter gegen diese Strahlenart erweist als das Myeloidgewebe).

Vom Thorium und Radium sind nach kleinen Dosen Zellvermehrungen speziell lymphocytärer Natur (Gudzent) berichtet worden. Von den Röntgenstrahlen ist derartiges bisher nicht bekannt geworden. Das alles scheint dafür zu sprechen, dass die freien Lymphocyten das empfindlichere Substrat gegenüber diesen Strahlenwirkunger sind.

Wir werden jetzt im folgenden kurz nach den Protokollen die Ergebnisse unserer Bestrahlungen am hämopoetischen Apparat (Knochenmark und Milz) schildern und sehen, ob und in welcher Weise sie mit dem Blutbefund in Beziehung stehen und den letzteren erklären.

\section{Histologische Befunde.}

Die hämopoetischen Organe wurden teils in Orthscher Lösung (Formol-Müller) fixiert und dann nach Pappenheim in May-Giemsa gefärbt, oder in Formol-Alkohol: 90proc. Alkohol $=70$ Teile, 10 proc. Formol $=30$ Teile fixiert und in Methylgrün-Pyronin gefärbt.

\section{Schwarzes Kaninchen.}

Milz: Die Follikel zeigen kanm einen leichten Grad ron Atrophie; sehr deutlich ist diese Follikelatrophie jedenfalls nicht. Die Pulpa ist ausserordentlich blutreich und pigmenthaltig ohne direkt als hypertrophisch angesprochen werden zu können. Myeloide Umwandlung war nicht vorbanden.

Knochenmark: Hier besteht eine deutliche Hyperplasie. Das Mark der langen Röhrenknochen ist ausserordentlich zellreich. Keine Spuren von Zell- oder Kernzerfall oder sonstiger Schädigung der Zellen. Besonders schön erhalten und vermehrt sind die Megakaryocyten. Das Fettgewebe ist geschwunden und durch Knochenmarksgewebe ausgefüllt.

\section{Graues Kaninchen.}

Milz: Follikel nicht atrophisch. Pulpa keine myeloide Cmwandlung, dagegen starker Blutreichtum, viel Pigment und Pigmentzellen. Die ganze Milz ist besonders in der Pulpa völlig durchsetzt mit einer enormen Menge ron Plasmazellen.

Knochenmark: Auch hier besteht ein Zustand beginnender Hyperplasie mit beginnendem Schwund des Fettgewebes. Die Megakaryocyten sind gut erbalten. Auch hier finden sich zahlreiche Plasmazellen vom Marschalkoschen Typus, wenn auch nicht so reichlich als in der Milz. Doch finden sich auch myeloblastische Reizungsformen.

Vergleichen wir die histologischen Resultate unserer allerdings an Zahl nur geringen Versuche, die sich im Ergebnis indessen im wesent- 
lichen gleich verhalten mit denen von Heineke und von Ziegler, so finden auch wir, ebenso wie Ziegler, einen hypertrophischen Zellreichtum des myeloiden Gewebes im Knochenmark und einen grossen Blut- und Pigmentreichtum sowie Plasmazellbildung der Milzpulpa. Dagegen will Heineke Atrophie auch des Knochenmarks gesehen haben.

Was wir nicht finden, ist die Atrophie des lymphadenoiden Gewebes und die myeloide Milzmetaplasie, die er konstant beachtet hat, ebenso wie Heineke, und die er zum Ausgang seiner Leukämietheorie gemacht hat.

Es scheint mir nach alledem höchst wahrscheinlich, soweit es gestattet ist, aus unserer nur kleinen Zahl von Versuchen, Schlüsse zu ziehen, dass die Lymphknötchenatrophie ebenso wie die myeloide Metaplasie an der Milz sich erst im Laufe der Zeit nach protrahierteren Bestrahlungen geringerer Intensität herausbilden kann, und dass sie die Folge, nicht die Ursache einer, dann also primären Myeloidgewebswucherung ist.

Bei der kurzen Zeit, die unsere Tiere nach den intensiven Bestrahlungen lebten, hatten die Follikel sozusagen keine Zeit, unter dem Druck der myeloiden Reaktion in Atrophie zu geraten. Durch die Strahlen selbst wurden sie direkt aber nicht zerstört. Unsere Absicht mit den grossen Dosen war aber nicht, eine Leukämie zu erzeugen, sondern das primum movens, das empfindlichste Substrat der Strahlenwirkung festzustellen. In dieser Hinsicht sind gerade unsere Versuche mit den grossen Dosen besonders lehrreich, da sie zu lehren scheinen, dass nicht die Follikelatrophie das primäre, sondern das sekundäre ist. In erster Linie wirken denn auch die Röntgenstrahlen nach unseren Beobachtungen, ebenso wie das Thorium, auf das myeloide Gewebe und seine Zellen, und $z$ war in schwächeren Dosen jedenfalls reizend, in ganz starken vielleicht zerstörend, und eine im ersten Fall atrophizierende, im zweiten Fall etwaigc Reaktion auslösende Wirkung auf den Follikelapparat scheint darnach keine durch die Strahlung direkt bedingte, sondern viel eher eine so indirekt durch die untergeordnete Wirkung auf den myeloiden Apparat hervorgerufene zu sein.

Hiernach würde sich also die Röntgenstrahlung tatsächlich qualitativ nicht anders verhalten, wie die Thoriumwirkung, sondern nur noch graduell different. Bei unseren grossen und viel wirksameren Thoriumgaben wurde eben der myeloide Apparat sogleich total zerstört und das Blut von Lenkocyten völlig befreit. Das Lymphadenoidgewebe verhielt sich bei unseren Thoriumversuchen zum Teil ganz ebenso, wie es Ziegler bei seinen Röntgenbestrahlungen mit zwar kleineren Dosen aber viel protrahierterer Dauer in dem einen seiner Fälle (3) geschildert hat (bindegewebige Umwandlung). Auch der Pigmentgehalt und der Erythrophagismus der Milz ist nach unseren Röntgenbestrahlungen der gleiche, wie der beim Thorium beobachtete. Dass wir keine myeloide Umwandlung der Milz wie Ziegler feststellen konnten, hat ebenfalls wohl seine Ursache an der zu kurzen Wirkungsdauer der intensiven Strahlenmengen auf das Gewebe. Es stehen also unsere starken Röntgenbestrahlungen etwa in der Mitte zwischen Zieglers schwächeren protrahierten Bestrahlungen und mittelgrossen und grossen Thoriumbestrahlungen. 
Das histologische Ergebnis unserer Röntgenbestrahlungen wäre darnach also qualitativ völlig das gleiche wie das von $\mathrm{Ziegler,} \mathrm{mit} \mathrm{dem} \mathrm{einzigen}$ Unterschied, dass wir eine Follikelatrophie nicht in dem Masse wie dieser Forscher beobachten konnten, und wir daher inbezug auf die Deutung die erste sichtbare bistologische Wirkung der Bestrahlung nicht ins lymphadenoide Gewebe verlegen. Ob die Reizwirkung des Myeloidgewebes direkt durch die Bestrahlung ausgelöst oder von einer Zustandsänderung am Milzapparat bedingt ist, ist eine andere Frage.

Trotzdem wir stärkere aber Strahlen-Dosen wie Ziegler verwendeten, haben wir aber doch, abweichend von Heineke, im Knochenmark keine Zellatrophie, wie beim Thorium, selbst nicht einmal im Beginn befindlich, gesehen, sondern haben vielmehr mit Röntgenstrahlen stets nur einen starken Reizungszustand erhalten. Es wäre möglich, dass diese Differenz gegenüber Thorium darin liegt, dass man bei Thorium noch stärkere Mengen strahlender Energie einverleiben kann; indes Heineke will ja $\Lambda$ trophie schon bei seinen anscheinend geringeren Röntgenstrahlen erhalten haben. Das Fehlen der Lymphknötchenatrophie bezw. die noch stehengebliebenen Follikel können da nicht gut auf reaktive Reizung bezogen werden; denn die Follikel sind weder hyperplastisch noch haben sie Keimcentren. Aber auch die zweifellos gegenüber den lympathischen Apparat erst primäre myeloide Knochenmarksreizung braucht nicht unbedingt absolut direkte Folge der Strahlenwirkung zu sein, sondern kann indirekte Strahlenwirkung sein, hervorgerufen durch einen Reiz, den die durch die Strahlen geschädigte oder sonstwie affizierte Milzpulpa auf das Knochenmark ausübt. Auffallend und der Erklärung bedürftig ist nach alledem nur noch das Verhalten des Blutes, die starke Lymphopenie. Wir haben nämlich im Blut eine lymphocytäre Leukopenie mit relativer Granuloleukocytose, im Gewebekeine Lymphknötchenatrophie, aber einen deutlichen Reizungszustand des Knochenmarks beobachtet. Ziegler sieht das Primäre in der Lymphknötchenatrophie, deren Folge einerseits die Lymphopenie, andererseits die Knochenmarksreizung und eine leukämoide Granuloleukocytose sein soll. Es ist die Frage, ob nicht das Primäre in der Knochenmarksreizung bezw. in der Lymphocytolyse des Blutes liegt.

Auch wir haben, ebenso wie Ziegler, eine Abnahme der Leukocyten im Blute festgestellt, und zwar an den Lymphocyten stärker wie an den Leukocyten, nur dass unsere absoluten Zahlenverminderungen, entsprechend den grösseren Strahlendosen, noch grössere waren. (Dass bei Thorium das Blut völlig von Leukocyten befreit wurde, liegt an der stärkeren Intensität der viel grösseren Thoriumgaben. Diese Blutveränderung ist beim Thorium auch hinreichend erklärt durch die völlige Zerstörung des Knochenmarks.)

Beim Thorium blieb unerklärt allein der Umstand, dass, obwohl die Lymphknötchen nicht völlig zerstört wurden, trotzdem im Blut die Lymphocyten völlig fehlten, ja sogar früher schwanden wie die Leukocyten. Hier bei den Röntgenstrahlen ist es ganz ebenso auffallend und schwer erklärlich, dass das Blut an farblosen Blutzellen und speziell auch an solchen des Lymphadenoidgewebes verarmte, obwohl die Lymphknötchen nicht 
besonders atrophisch waren, und auch an Leukocyten, obwohl das Knochenmark sogar in einem gewissen hyperplastischen Reizungszustand angetroffen wurde.

Selbst wenn man mit Helber-Linser ${ }^{1}$ ), Curschmann-Gaupp ${ }^{2}$ ) [aber Heineke sowie Klieneberger-Zöppritz ${ }^{3}$ ) sind anderer Ansicht] annehmen wollte, dass beim isolierten Bestrahlen der Milz das Knochenmark nur indirekt beeinflusst und $z$ war in regenerative Reizung versetzt würde, sozwar dass sich cholinartige intermediäre Leukotoxine bilden, welche in erster Linie die circulierenden Leukocyten des Blutes zur Leukolyse und dadurch zur Leukopenie bringen, die dann das Knochenmark zu ersetzen trachtet, wobei also jedenfalls in erster Linie die circulieren den Leukocyten der Vernichtung anheimfielen: so ist es doch auffallend, dass diese Leukopenie nicht nur bei unseren Versuchen mit kurzer Lebensdauer des Tieres und exorbitant starken Bestrahlungen, sondern auch bei Ziegler in der überwiegenden Zahl seiner Versuche mit schwächeren Strahlen eine andauernde war; trotz des Reizungszustandes im Mark nämlich wurde weder die Zellzahl völlig ergänzt, noch traten regenerative Jugendformen im Blute auf.

Dieses ist aber doch wohl nur so zu erklären, dass die gebildeten und sich immer vermehrenden Leukotoxine wirksam genug sind, um auch den event. Nachschub der jugendlichen Zellen fort und fort zur Leukolyse zu bringen. Mit anderen Worten, dass die deletäre Wirkung der Strahlen auf das Blut stärker ist als die Reizwirkung auf das Knochenmarksgewebe. Oder aber man muss annehmen, dass die Bestrahlung nur die Zellmobilisation nach der Zellbildung lähmt, für welche Annahme es bisher an greifbaren Unterlagen fehlt. Anders ist es nicht zu erklären, dass wir völlige Blutzellverarmung besonders der Lymphocyten im Blut finden ohne Atrophie der Lymphknötchen und mit myeloider Zellreizung im Knochenmark. Das gilt wenigstens für das normale Tier.

Dass bei krankhaft leukämischer Knochenmarkswucherung die blosse Bestrahlung der Milz auch die myelogene Knochenmarkswucherung hintanhält, ist dagegen durch die Tatsachen erwiesen. Speziell wird die Annahme, dass der zellreiche Reizzustand des Knochenmarks bei unseren Versuchen etwa nur ein indirekt regenerativer sei - bedingt durch die Leukolyse im Blut —, widerlegt durch die direkt myelotoxische Wirkung noch stärkerer Mengen strahlender Energie, wie wir sie beim Thorium zu sehen bekommen. Allerdings wird das Thorium dabei in die Gefässbahn eingeführt, von wo es direkt ins Knochenmark gelangt, während die Röntgenstrahlen nur auf die Milz appliziert werden und von hier nur indirekt irgendwie das Knochenmark alterieren.

Bemerkenswert bleibt nach alledem nur noch der Umstand, dass, bei der Bestrahlung der gesunden Milz selbst mit unseren hohen, also nicht einfach reizenden Dosen, ein zellreicher Reizzustand des Knochen-

1) Münchener med. Wochenschr. 1905. Nr. 15. Deutsches Arch. f. klin. Med. Bd. 83.

2) Münchener med. Wochenschr. 1905. Nr. 50.

3) Ebenda. 1906. Nr. 18 und 19. 
marks neben der Leukopenie erzielt wird, während bei der Bestrahlung der kranken myeloleukämischen Milz ausser der Leukopenie des Blutes auch eine Wachstumshemmung der myeloischen Wucherung erzielt wird. Das Aultreten von Reizungszellen im Blut wird durch den grossen Gehalt des hämopoetischen Gewebes an Plasmazellen hinreichend erklärt.

Wir haben somit folgendes festzuhalten: Beim Thorium eine totale (temporäre) Entvölkerung des normalen Blutes, auch an Lymphocyten, bei völliger Verödung des Marks, trotz nicht ganz völliger Zerstörung des Lymphknotenapparates und des lymphadenoiden Gewebes. Bei Röntgenstrahlen eine starke nicht völlige Entvölkerung des Blutes, ausser an Lymphocyten auch an Leukocyten, trotz bestehenden Reizzustandes des Knochenmarks und ohne Atrophie der Lymphknötchen.

Im speziellen bei Röntgenstrahlen eine Differenz zwischen gesundem und krankhaftem (leukämischem) myeloischen Apparat, insofern als der letatere stärker reagiert und in seiner Wucherung beschnitten wird; ferner bei gesundem Organismus eine Differenz zwischen Blut und hämopoetischem Gewebc; wir sehen, dass die Blutlymphocyten empfindlicher erscheinen und eher vernichtet werden als die Gewebslymphocyten. Es wirken also an gesunden Tieren die Röntgenstrahlen zerstörend anscheinend vor allem und besonders kräftig auf das circulierende Blut, speziell auf dessen Lymphocyten ein, (ausserdem atrophisierend auf die Milzpulpa und reizend auf das Knochenmark); beim leukämischen Organismus dagegen stärker auf das hämopoetische Gewebe und hier stärker zerstörend auf das myeloidwuchernde.

Das Gemeinsame der Thorium- und Röntgenstrahlenwirkung ist sonach folgendes: Kleine Thorium- und Röntgenstrahlen bewirken Hyperleukocytose, grosse Röntgen- und Thoriumstrahlen Leukopenie; dabei aber Röntgenstrahlen eine Reizung, Thorium eine Zerstörung des Myeloidgewebes. Bei Thorium wie bei Röntgenstrahlen findet sich stets Pigmentzerfall und Erythrophagismus in der Milz. An sonstigen Organen bei Röntgen nichts Besonderes. Nur einmal berichtet Ziegler von beginnender Lebernekrose (Fall 3). Bei Thorium oft Leberschädigung.

C.

Wir wenden uns jetzt zum Bericht über unsere systematischen Versuche mit Benzol und Benzin. Es wurden diese Stoffe mit Oleum olivarum vermischt subcutan injiziert.

\section{Vorversuche.}

Explorative Vorversuche ergaben, dass für Kaninchen von $1500 \mathrm{~g}$ Körpergewicht $3-31 / 2$ cem Benzol, zu gleichen Teilen mit Olivenöl vermischt und subcutan einverleibt, die höchst erträgliche Dose vorstellten. Bei 4 cem Benzol schrieen die Tiere oft minutenlang unter schwerer Dyspnoe, und wohl auch vor Schmerz unter der starken lokalen Reizwirkung; bei über $4 \mathrm{ccm}$ Benzol traten fast regelmässig Lähmungen der Extremitäten auf. In einem Falle Hirnherdsymptome (Hirnblutung in der Brückengegend?). Bei $5 \mathrm{ccm}$ und mehr erfolgte regelmässig der Tod innerhalb $1 / 4-1 / 2$ Stunde. 
Toluol und Xylol setzten dieselben Zellveränderungen im Blut, wurden aber noch schlechter vertragen. Ich nahm deshalb von weiteren Versuchen mit diesen Mitteln Abstand.

Demgegenüber wurde Benzin in gleichen Dosen von gleich schweren Tieren noch anstandslos vertragen; auch $8 \mathrm{ccm}$ Benzin zeigten noch keine irgendwie auffallenden Allgemeinerscheinungen. Erst nach einer Injektion von 9-10 cem trat der Tod im Verlauf des folgenden Tages ein.

Aber noch ein anderer Grund war Ursache, auch die Wirkungen des Benzins auf den hämopoetischen Apparat näher zu studieren. Es zeigte sich nämlich, was auch schon Selling festgestellt hatte bei einer Vorversuchsreihe, dass sehr kleine Reizdosen von Benzol $(0,5-1 \mathrm{ccm})$ eine deutlich ausgesprochene Hyperleukocytose durch Vermehrung der reifen polynucleären amphooxyphilen Spezialzellen und Mastzellen bei relativer Abnahme der Lymphocyten und Fehlen der Eosinophilen nach sich zogen ${ }^{1}$ ), während Benzin in gleichen kleinen Dosen sogleich regelmässig bereits eine ausgesprochene, allerdings nur relative Ly m $p$ hocytose bei normaler Leukocytenzahl erzeugte ${ }^{2}$ ). Hier schien also prima vista ein qualitativer Antagonismus vorzuliegen, Benzol ein Leukotacticum, Benzin ein Lymphotacticum zu sein.

Auch hier konnte die Deutung theoretisch eine zwiefache sein. Dass das Benzol in kleinen Dosen schon den doch nach Uebereinstimmung aller Autoren relativ unempfindlichen Lymphocytenapparat zur Unterdrückung gebracht hätte, und dass dadurch, im Sinne Zieglers, eine hypercompensatorische Hyperleukocytose der Granulocyten entstehen konnte ${ }^{3}$, hat nicht viel Wahrscheinlichkeit für sich. Viel wahrscheinlicher ist es, dass dieses Mittel, welches in den wirksam grossen Dosen den Leukocytenapparat zerstört, in kleinen Dosen auf eben denselben anreizend wirkt. Dieser Anreiz kann ein direkt an dem hämopoetischen Apparat und seinen Zellen angreifender irritierender Stimulus sein, er kann aber auch, ähnlich wie die Nucleinsäure, vom Blut aus chemotaktisch die Zellen zur funktionellen Betätigung herauslocken. Im Sinne dieser letzten Auffassung könnten die Experimente von J. Loeb sprechen, nach denen eine oberflächliche Lipolyse der Zellmembran Ursache der Amöbidität und der migratorischen Lokomobilität sein soll. Ein sicherer Entscheid zwischen beiden Auffassungen ist auch post mortem schwer zu treffen, denn nach beiden Reizungen, der direkt stimulierenden und der reaktiv chemotaktischen, kommt es ja zu den gleichen Zellvermehrungen. Wahrscheinlich dürften ausserdem meist auch beide Reize miteinander kombiniert wirksam werden. Immerhin sei erwähnt, dass bei fortgesetzter Applikation so kleiner Benzoldosen die Hyperleukocytose schliesslich in eine regenerative Phase trat, und dass hierbei ganz die gleichen unreifen Zellformen mit basophilem Plasma, stark basophilen, mastkornähnlichen, sehr rarefizierten Körnchen und stark vacuolisiertem Plasma beobachtet wurden, wie ich sie bei meinen

1) Leukocyten 16000 , darunter Spezialleukocyten $75 \mathrm{pCt}$., Monocyten $8 \mathrm{pCt}$, Mastzellen 2pCt., Lymphocyten $15 \mathrm{pCt}$.

2) Leukocyten 10000 , Spezialleukocyten $22 \mathrm{pCt}$, Lymphocyten $78 \mathrm{pCt}$.

3) Dass also Benzol direkt Lymphopenie, Benzin Lymphocytose macht. 
Versuchen über kombinierte Saponin-Nucleinsäurewirkung am Kaninchen gemeinsam mit Szecsi beobachtet, beschrieben und abgebildet habe ${ }^{1}$ ). Eine starke Leukopenie konnten wir selbst auch bei durch Iängere Zeit fortgesetzten kleinen Benzoldosen nicht erzeugen.

Dagegen bewirkten grosse Benzoldosen (3-4 g) Leukopenie und zwar mit relativer Neutropenie, d. h. relativer Lymphocytose, vermutlich infolge starker Zerstörung und Suppression des empfindlichen Leukocytenapparates mit relativem Uebergewicht des resistenten Lymphocytenapparates. Somit finden wir, dass kleine Dosen Benzol leukotaktisch, grosse Dosen negativ leukotaktisch aggressiv, i. e. leukopenisch und relativ lymphocytotisch wirken. Eine so absolute Entvölkerung des Blutes von Jueukocyten, wie wir sie mit Thorium erzielen konnten, haben wir indes selbst bei fast 2 Wochen fortgesetzten Gaben grosser Benzoldosen bei unseren Versuchen nicht erzielt.

Wie ist nach allem nun die Benzinlymphocytose durch kleine Benzindosen zu erklären? Entweder man könnte annehmen, dass das Benzin qualitativ derartig beschaffen sei (und dadurch unseren therapeutischen Absichten entgegenkommt), dass es in gleich kleinen Dosen wie das Benzol, viel stärker als dieses wirksam, den leukocytären Apparat nicht erst zur Reizung, sondern direkt sogleich zur Suppression bringt und dadurch sogleich (also schon in diesen kleinen Dosen) indirekt eine Lymphocytose zur Auslösung bringt, ebenso wie Benzol dies in grösseren Dosen tut. Benzin würde dann qualitativ ebenso wie Benzol wirken, nur graduell sehr viel stärker und schon in kleinen Dosen dasselbe erzielen, wie Benzol in grossen, nur unter geringeren unerwünschten neurotoxischen Nebenwirkungen. In diesem Sinne könnte der Umstand sprechen, dass schon bei kleinen Benzindosen nicht absolute Hyperlymphocytose, sondern nur relative Jymphocytose eintritt, also dasselbe Blutbild wie bei starken Benzoldosen. Würde das der Fall sein, so hätten wir in dem Benzin ein Mittel, welehes vor dem Benzol in der in Rede stehenden Hinsicht bedeutende Vorzüge hätte, nämlich neben der leichteren Diffusibilität, Exhalier- und Verbrennbarkeit, die viel stärkere Wirkung auf den myeloischen Apparat in verhältnismässig kleinen Dosen.

Die andere Möglichkeit wäre die, dass, wie das Benzol elektiv auf den Leukocytenapparat in kleinen Dosen reizend, in grossen zerstörend wirkt, ebenso das Benzin in gleicher Weise spezifisch auf den Lymphocytenapparat wirksan sei. Wäre das der Fall, dann müsste das Benzin in grossen Dosen auch die Lymphocytenbildung und Ausfuhr völlig unterdrücken. Dann aber müssten kleine Dosen absolute Hyperlymphocytose erzeugen, was in unseren Versuchen nicht der Fall gewesen ist. Immerhin wird auch diese Hypothese wohl aufstellbar, wenn man annähme, dass das Benzin einen blanderen Reiz setzt, als das eingreifendere Benzol; wissen wir doch, dass stärker reizende Noxen (Nucleoproteid der Eiterkokken, Krotonolsäure, Abrin) Leukocytose und Eiterung durch Reiz auf den Leukocytenapparat ausüben, dass dagegen die Lipoide der chronische Entzündung und Granulombildung erregenden Bakterien eine Lymphocytose unterhalten.

1) Pappenhoim und Széesi. Folia haematol. 1912. XIII. 
Für diese Auffassung könnte die Tatsache und das Versuchsergebnis sprechen, dass bei einem Tier, dem Benzin + Benzol aa 0,1 eingespritzt wurde, eine Hyperleukocytose beobachtet wurde, bei der neben den polynucleären Leukocyten auch die Lymphocyten an der absoluten Vermehrung der Zellen beteiligt schienen ${ }^{1}$ ). Dann wäre das Benzin qualitativ in seiner stimulierenden Chemotaxis rom Benzol different. Gegen diese Auffassung spricht indes der Umstand, dass bei der stärkeren Benzolapplikation allein blosse relative Lymphocytose bei annähernd normaler absoluter Leukocytenzahl zur Beobachtung kam, dass also die Polynucleären absolut und relativ stark zurückgedrängt erscheinen, desgl. dass, wie schon erwähnt, kleine Dosen keine Hyperlymphocytose erzeugten.

Wir haben auch Versuche mit alternierender Applikation kleiner Dosen von Benzol und Benzin angestellt und haben dabei konstatiert, dass, nachdem Benzol zwei Tage lang eine ausgesprochene und deutliche Hyperleukocytose hervorgerufen hatte, eine einmalige Injektion von Benzin sofort eine ausgesprochene Leukopenie mit relativer Lymphocytose hervorrief. Umgekehrt gelang es nicht, nach einer Benzineinwirkung mit sekundärer relativer Lymphocytose, durch Applikation kleiner Benzolmengen wieder eine Hyperleukocytose hervorzurufen; im besten Fall gelang es, das Proportionsverhältnis zwischen Lymphocyten um ein weniges zugunsten der Leukocyten zu verschieben.

Während nun fortgesetzte kleine Benzoldosen die Hyperleukocytose unterhielten und steigerten, verursachten selbst lange fortgesetzte kleine Benzindosen niemals Hyperleukocytose, sondern immer nur relative Lymphocytose mit immer stärkerer Stejgerung des lymphocytären Proportionsverhältnisses. Dazu ergaben auch schon mittelgrosse Benzindosen ebenso eine deutliche Leukopenie mit relativer Lymphocytose.

Ein gleiches Blutbild, Leukopenie mit relativer Lymphocytose, erhielten wir allerdings ja auch beim Benzol, aber nur bei Verwendung grosser Dosen, so dass also in bezug auf das Blutbild mittlere Dosen Benzin $(4 \mathrm{ccm})$ denselben Effekt hatten wie grosse Benzoldosen $(3 \mathrm{ccm})$. Mischungen kleiner Benzol- $(1 \mathrm{ccm})$ und mittelgrosser Benzindosen $(3-4 \mathrm{ccm})$ addierten sich in der Wirkung derart, dass das Benzin prävalierte, d. h. es entstand deutliche Leukopenie mit relativer Lymphocytose.

Die wahre Analyse des Wirkungsmechanismus kann natürlich erst die histologische Untersuchung erbringen, d. b. mit anderen Worten welche von unseren Veränderungen zur Erklärung der beiderseitigen Blutwirkung die richtige ist und der Wirklichkeit entspricht, wird und kann sich naturgemäss erst zeigen, wenn wir das Prinzip der Wirkung am hämopoetischen Apparat selbst, bei dessen histologischer Untersuchung, festgestellt haben werden.

Erwähnt mag indes zu dieser Frage noch hier schon werden, dass wir aus einer zu diesem Zwecke angestellten kleinen Versuchsreihe den $28 \mathrm{pCt}$.

1) Leukocyten 14500 , darunter polynucleäre Spezialzellen 72 pCt., Lymphocyten 
Eindruck gewonnen haben, dass nach dem Aussetzen der Applikationen das Blutbild sich bei den Benzintieren rascher ad integrum zur ückfindet (3-4 Tage), als bei den Benzoltieren nach entsprechenden grossen Dosen (8-10 Tagen). Indessen sind nach dieser Hinsicht unsere Versuche nicht zahlreich genug gewesen, um hier schon eine Gesetzmässigkeit mit Bestimmtheit aufstellen zu können.

Ganz besonders aber möge schon jetzt hervorgehoben werden, dass wir in keinem einzigen unserer Versuche weder mit Benzol noch auch selbst mit Benzin, selbst bei lange fortgesetzter Einverleibung, eine derartige schnelle absolute Leukopenie und totale Befreiung des Blutes von Leukocyten erzielt haben, wie wir sie experimentell bei Thorium nach einer einzigen maximalen Injektion erhalten hatten. Unsere bei Benzol und Benzin beobachteten Leukopenien gingen unter eine Zahl von 700 Leukocyten pro $1 \mathrm{cmm}$ Blutes nicht herunter.

\section{Figentliche Versuche (Versuche mit Benzol und Benzin).}

\section{A. Benzolversuche.}

\section{Wirkung anf das Blut.}

Vorbemerkung: Selling spritzte im Durchschnitt $2 \mathrm{ccm}$ Benzol täglich 2-9 Tage lang ein, worauf die Tiere nach längerer oder kürzerer Zeit eingingen. Dabei fand er starke Reduction der Leukocytenzahl (gelegentlich 700 pro $1 \mathrm{cmm}$ Blut) vornehmlich bedingt durch Verschwinden der polynucleären Leukocyten aus der peripherischen Circulation (entsprechend der prävalierenden Wirkung des Benzols am myeloischen Apparat). Der Leukopenie geht oft eine temporäre initiale oder prodromale Hyperleukocytose voraus.

Wir haben, um das Prinzip der Benzolwirkung und ihre sonstigen toxikologischen Eigenschaften festzustellen, grössere Dosen als Selling verabfolgt. Dieser gab $1 \mathrm{ccm}$ pro $1 \mathrm{~kg}$ Körpergewicht; wir haben ausser solchen kleinen Dosen meist das doppelte und dreifache gegeben.

$\mathrm{Da}$ wir das Benzol nur in Rücksicht auf seine antileukocytäre Wirkung studierten, haben wir dem Erythrocyten- und Plättchenbefund am Blut nur in qualitativer Hinsicht Aufmerksamkeit geschenkt. Es sei vorweg bemerkt, dass wir auffällige Besonderheiten hier weiter nicht bemerkten. Es sei denn, dass die Plättchen im Blut persistierten, obwohl gelegentlich die Megakaryocyten im Mark völlig geschwunden schienen.

Auszüge aus den Protokollen einiger besonders histologisch instruktiver Versuche.

Kaninchen 191. Gewicht 1300 g. Blut: normale Verhältnisse mit relativer physiologischer Hyperlymphocytose. Leukocytenzahl 13000 .

16. 9. Benzol $1,0 \mathrm{ccm}+$ Oleum olivarum 6,0 .

17. 9. Leichter Grad von Hyperleukocytose $(\mathbf{1 6 0 0 0})$ durch die polynucleären Spezialzellen bedingt. Neben den polynucleären Spezialleukocyten finden sich nur noch Lymphocyten, Mastzellen und spärliche Reizungszellen. Eosinophile und grosse Lymphoidzellen fehlen. Benzol 2,5 + Oleum olivarnm 4,0.

18. 9. Deutlicher Leukocytensturz (10000), indes immer noch mit Prävalenz 
der polynucleären Leukooyten. Hier und da ein paar Reizungszellen, sonst keine pathologischen Zellformen. Benzol 2,0 + Oleum olivarum 8,0.

19. 9. Leukocyten von gleicher $\mathrm{Zahl}$ und mikroskopischem Verhalten wie gestern. Es prävalieren noch immer die polynucleären Leukooyton. Grosse mononucleäre Lymphoidzellen werden nicht beobachtet, desgleichon keine Eosinophile. Benzol $4,5+$ Oleum olivarum 6,0 .

21. 9. Starke Leukopenie (4000). Das Verbältnis der Polynucleären zu den Leukocyten hat sich umgekehrt. Es werden im mikroskopischen Präparat fast nur nooh kleine Lymphocyten gefunden.

22. 9. Benzol 2,0 + Oleum olivarum 6,0. WeitereAbnahme der Leukocyten (2100), Neben den immer noch präralierenden kleinen Lymphocyton werden heute wieder өinige polynucleär granulierte Leukocyten gefunden.

Benzol 4,0 + Oleum olivarum 4,0. Exitus nach $1 / 2$ Stunde.

Bei der Nekropsie erscheint das Knochenmark dunkelrot, die Knoohenkapsel nicht mehr ganz ausfüllend, aber noch gut konsistent. Die Milz klein und dunkel. Leber, Niere, Lunge, Nebenniere ohne äusserliche Besonderbeiten.

Kaninchen 201. Gewicht 1920 g. Blut mikroskopisob ohne Besonderheiten. Leukocyten (10200).

28. 9. Benzol $3,0+$ Oloum olivarum 6,0 .

29. 9. Deutlicher Leukocytensturz (3900). Starke relative Lymphocytose. Mikroskopisch findet man nur noch vereinzelt polynucleäre Granulocyten. Benzol 1,5 + Oleum olivarum 6,0 .

30. 9. Vermebrung der Leukocyten gegen gestern (6500). Mikroskopisch finden sich wieder stärker polynucleäre Leukocyten noben den Lymphocyten. Auch die Mastzellen sind wieder in grösserer Menge vorhanden. Benzol 3,0 + Oleum olivarum 6,0 .

1. 10. Erneute Abnahme der Leukocyten (1900). Die Polynucleären haben ebenfalls wieder abgenommen. Die Zellzahl ist also auf Kosten der Polynucleären vermindert. Mikroskopisch an den Zellen nichts Besonderes. Benzol 2,0 + Oloum olivarum 6,0 .

2. 10. Leukocyten (1100). Mikroskopisch finden sich ausserordentliob wenige leukocytäre Elemente, dieselben sind ausschliesslich Lymphocyten. Benzol 2,0 +Oleum olivarum 8,0 .

3. 10. Das 'Tier wird getötet.

Nekropsie: An den Organen äusserlich, abgesehen von starker Anämie, nichts Besonderes, speziell nicht an Leber und Nieren. Die Milz ist wobl entwickelt und von normaler Farbe. Das Knochenmark ist nur an den oberen Epiphysen dunkelrot, in den Diaphysen aber graurot fetthaltig.

Das Ergebnis unserer Benzolversuche in bezug auf das Blut steht im grossen und ganzen völlig in Uebereinstimmung mit den Ergebnissen von Selling. Es ergibt sich aus unserer Benzolversuchsreihe, dass das Benzol schon in Dosen von $4 \mathrm{ccm}$ nicht mehr vertragen wurde, dass es in ganz kleinen Dosen $(1-2 \mathrm{ccm})$ bei mittelstarken Tieren eine Hyperleukocytose durch Vermehrung der polynucleären Spezialleukocyten hervorrief $^{1}$, dagegen bei unseren grösseren Dosen $(3-4 \mathrm{ccm})$ eine hochgradige

1) Und zwar fanden wir diese Hyperleukocytose bei kleinen Dosen stellenweise ziemlich anbaltend; erst bei grösseren Dosen erhielten wir Leukopenie. Auch Selling hat bei seinen kleinen Dosen Hyperleukocytose beobachtet, aber nur vorübergebend als initiale Leukocytose. Sie wurde sehr bald von Leukopenie abgelöst und gefolgt. 
leukopenische Verminderung (1190) der Leukocyten mit relativer Hyperlymphocytose, d. h. also mit relativer Granuloleukopenie. Die kleinen Dosen bewirken also wohl fraglos eine chemotaktische Reizung, die grossen eine Abnahme der polynucleären Blutleukocyten. Ob diese auf Zerstörung der Zellen im Blut, auf Behinderung ihrer Zellbildung, d. h. Zerstörung dieser Zellen im Knochenmark, oder bloss behindertem Uebertritt aus dem Knochenmark ins Blut beruht, wird die histologische Untersuchung zeigen müssen. Die histologische Untersuchung wird dabei auch die relative Lymphocytose zu erklären haben, die bei grösseren Dosen wohl nicht einfach durch direkte Reizung der Lymphocyten zustande kommt, sondern, was wahrscheinlicher sein dürfte, nur indirekt durch irgendeine abstossende Wirkung auf die Leukocyten.

Der Unterschied gegenüber Röntgen- und Thoriumstrahlen scheint hiernach der zu sein, dass die Lymphocyten sich bei Benzol in unseren Versuchen resistenter erwiesen als die Granulocyten und nicht aus dem Blut ganz zum Verschwinden gebracht werden konnten, vielmehr immer noch persistierten, wenn die Granulocyten schon so gut wie völlig verschwunden sind, während sie bei Röntgen- und Thoriumstrahlen zuerst weichen.

\section{Histologische Untersuchung.}

Vorbemerkung. Es konnte selbstverständlich nicht unsere Absicht sein, die toxikologische Giftwirkung der in Rede stehenden Stoffe histologisch nach allen Richtungen zu verfolgen. Wir haben daher rorläufig von dem Bericht über die Ergebnisse der Spezialfärbungen etwa in bezug auf Nervenstrangdegenerationen, Verhalten der Gefässelastica, Verhalten der Lipoide in Leber und Nebennieren, sowie der Glykogenverteilung Abstand genommen und beschränken uns vor der Hand allein auf das allgemein histologische Verhalten der Organe. Allein am hämopoetischen Apparat haben wir die für denselben in Betracht kommenden spezielleren Färbungen in notwendigen Fällen mit herangezogen.

Im allgemeinen begnügten wir. uns mit allgemeinen histologischen Uebersichtspräparatfärbungen, wie sie in ganz vorzüglicher Weise durch die neue kombinierte May-Giemsa-Essigsäuremethode zum Ausdruck gebracht werden, welche Methode ganz wundervolle Differenzierungen, ausser am hämopoetischen Apparat speziell an Niere und Hypophyse, nächstdem an Leber, Nebenniere, Lunge und, nach Formol-Alkohol-Fixation, auch an dem Centralnervensystem ergibt. Sie gibt hier in einfachster Weise ganz hervorragend schöne Nisslfärbung der Ganglienzellen. Die Organe wurden fixiert in dem für diese $Z$ wecke meist vorzüglichen Orthschen Gemisch (Müller-Formol), welches besonders für den hämopoetischen Apparat völlig ausreichend ist.

Aus den Ergebnissen Sellings sei kurz rekapituliert, dass dieser Forscher in der Milz zwar ein Hervortreten der Keimcentren der Malpighischen Körperchen wahrgenommen haben will, dass er aber in der kleinzelligen Zone der Follikel Zeichen des Zellzerfalls, pyknotische und karryorrhektische Kerne beobachtet haben will, ähnlich wie wir sie beim Thorium fanden. In den Sinus fand er mononucleäre Pigmentzellen, 
in den Pulpasträngen kleine Lymphocyten, grosse Zellen mit breitem Plasma und viel Polynucleäre.

Im Knochenmark fand er, ganz wie Heineke bei Röntgenstrahlen, eine A trophie des Knochenmarks, und zwar sollen hier die lymphoiden Zellen stärker resistent sein als die Granulocyten. Er betont also, dass das myeloide Gewebe stärker geschädigt wird als das lymphadenoide, wie ja auch im Blut dio Polynucleären stärker von der Reduktion betroffen sind als die Lymphecyten.

Folgendes sind unsere Befunde speziell hinsichtlich der oben erwähnten Tiere:

Kaninchen 191. Das Knochenmark (der langen Röbrenknochen) zeigt vor allem ausserordentlich starke Hyperämie.

Die Gefässe sind stark erweitert und strotzend mit Blat gefüllt.

Die normale Fettgewebszeichnung ist verwischt, wenn auch vorhanden und nicht durch Hyperplasie des Zellparenchyms verloren gegangen, sondern in einem collabiert atrophischen Zustand begriffen.

Das Knochenmark ist zellarm, indessen nicht in besonders auffallender Weise; speziell sind oxyphil- und amphooxyphilgekörnte Zellen and vor allem auch Megakaryocyten in reichlicher Menge rorhanden. Die Iymphoiden Zellen auffallend spärlich oder fehlend.

Die Milz zeigt histologisch keine Besonderheiten, speziell weder Lymphknötchenatrophie noch myeloide Pulpametaplasie. Sie ist dagegen strotzend mit Blut gefüllt and enthält in ihren Bluträumen zahlreicho pseadoeosinophilo Spezial loukocyten. Die Pulpa enthält im übrigen sehr viel Pigment und zeigt Erythrophagenbildung. An den Stellen, wo die Sinus besonders orwoitert sind, sieht man deutlich einen Uebertritt von kleinen Lymphocyten- and grossen endotheloiden Monocyten-Zellformen in das Blut.

Die Lungen sind stark ödematös mit seröser Flüssigkeit durchtränkt, sonst ohne Besonderheiten.

Die Leber: Es besteht diffuse parenchymatöse Hepatitis mit beginnendem Zerfall des Zellprotoplasma. Die Capillaren sind stark erwoitert und mit pseudooosinophilen Leukocyten angefüllt.

Nieren: Das Organ zeigt, besonders in der Rinde, in das Mark hinein verlaufende Züge beginnender Nekrobiose. Die Epithelien der Harnkanälchen färben sich hier nur noch sohwach diffus und rein oxyphil. Die Kerne sind ausserordentlich schwach färbbar. Es besteht eine äusserst starke Glomerulitis mit völlig verwischten Konturen der Glomeruli, dabei aber Kern- und Blutreichtum der Glomerulusschlingen. Nur hieran sind die Glomeruli noch als solche zu erkennen.

Nebennieren im allgemeinen ohne Besonderheiten. Das Mark ist reich an chromaffiner Substanz.

In Gehirn und Rückenmark zeigen die Ganglienzellen keinerlei besonders hervorstechende Abnormitäten; besonders ist die Tigroidsubstanz nach Form und Anordnung gut erhalten.

Also: mässige Knochenmarksparenchymatrophie bei stärkster hyperämischer Congestion und schwere Nephritis. Während das periphere Blut an Leukocyten verarmt ist, findet sich bei diesem Tier eine Ansammlung derselben in den inneren Organen.

Kaninchen 201. Das äusserst zellreiche Knochenmark der langen Röhrenknochen ist deutlich hypertrophisch, speziell durch Vermebrang der Granulocyten, während die lymphoiden Zellen eher vermindert als vermehrt schoinen. Megakaryocyten in Menge, keine Fettareolenstruktur. 
Milz ohne Besonderheiten. Keine Knötchenatrophie, keine myeloide Metaplasie. Das Organ ist äusserst blntreich und zeigt in den Bluträumen ausserordentlich zablreiche polynucleäre Granulocyten.

Darmfollikel (Appendix) obne Besonderheiten, speziell keine Atrophie.

Lungen ohne Besonderheiten des Gewebes. Die Bläschen sind allerdings röllig mit Blut gefüllt, doch dürfte das von der Art des unnatürlichen T'odes des Tieres durch Nackenschlag herrühren.

L $\theta$ b $\theta \mathrm{r}$ zeigt ausgedehnto, äusserst starke, berdwois angeordnete degenerative Fettmetamorphose des Parenchyms.

Nieren ohne Besonderheiten.

Nobennieren obne Besonderheiten, viel chromaffine Substanz.

Das histologische Ergebnis unserer angestellten Benzolversuche werden wir etwa folgendermassen zusammenfassen können:

Wir teilen die histologischen Befunde unserer Benzolversuche ein in solche am hämopoetischen Apparat (Knochenmark und Mil $\%$ ) und solche an den sonstigen drüsigen und parenchymatösen Organen.

Am hämopoetischen Apparat hatte Selling bei seinen Benzolversuchen an den Lymphknoten (ebenso wie Ziegler und Heineke bei Röntgenstrahlen) und am Knochenmark (ebenso wie Heineke bei Röntgenstrahlen) Atrophien festgestellt und zwar am Knochenmark stärker als am l,ymphfollikelapparat. Hier am Knochenmark will er, ebenso wie wir bei Thoriumversuchen, höhere Resistenz der Iymphoiden als der granulierten Zellen gefunden haben.

Wir haben beim Benzol, ganz wie Selling, ebenfalls meist eine mehr oder minder deutliche Knochenmarksatrophie, wie sie auch das Thorium setzt, nur in viel schwächerem Grade gefunden, dagegen in den Isymphknoten, abweichend von Selling und ähnlich wie bei Röntgenstrablen, einen Zustand von Indifferenz oder schwacher Reizung, jedenfalls niemals deutliche Atrophie, ja eher hier und da Bilder, die für beginnende Hypertrophie sprechen könnten. Dazu kommt, dass wir in der Milz Bilder von Uebergang lymphoider Zellen ins Blut, dagegen in einzelnen Fällen eine Anschoppung granulierter Blutleukocyten in Milz und Leber fanden.

Diese Differenzen zwischen uns und Selling dürfte dadurch bedingt sein, dass Selling fortgesetzt kleine Dosen $(1-2 \mathrm{ccm})$, wir kürzere Zeit grössere Dosen $(3 \mathrm{ccm})$ verabfolgt haben.

Das würde $\mathrm{zu}$ der von uns gefundenen relativen Lymphocytose ganz gut passen. Die Atrophie des Knochenmarks harmoniert ebenfalls mit dem Blutbefund, d. h. dem fast völligen Granulocytenschwund. Es schwinden also die Leukocyten aus dem Blut teils durch Ansammlung in den inneren Organen, tejls durch behinderte Nachbildung aus dem Knochenmark. Die Lymphocyten restieren, indem sie im Blut selbst nicht über die Norm zerstört werden, vielmehr von der Milz und den Lymphknötchen, wenn auch vielleicht nur in geringerem Masse, nachgeliefert werden. Wir fanden nämlich an den Lymphknoten ein ähnliches, allerdings nicht ganz identisches Bild wie bei der Röntgenisierung, am Knochenmark aber prinzipiell gleiche, wenn auch wesentlich schwächer ausgeprägte Bilder von Atrophie wie beim Thorium. Besonders erwiesen 
sich beim Thorium hier im Knochenmark die lymphoiden Zellen resistenter als die Granulocyten, während beim Benzol das umgekehrte der Fall zu sein scheint.

Im ganzen schienen also durch Benzol die Lymphknoten und Milz wenig, dagegen das Knochenmark schwerer geschädigt.

An den sonstigen Organen fanden wir an den Ganglienzellen des Centralnervensystems keine besonderen toxischen Störungen der Tigroidanordnung. An den Nebennieren und Lungen auch nicht irgendwie Besonderes. Am schwersten und zwar fast konstant verändert waren, ähnlich wie bei der Thoriumbestrahlung, als die hierbei empfindlichsten Organe, die lueber und besonders die Nieren. Hier fanden wir bei den von uns verabfolgten Dosen fast stets schwerere Formen, besonders parenchymatöser und glomerulitischer Nephriten; und zwar sind die Nierenentzündungen hier beim Benzol viel stärker als bei Thoriumbestrahlung, während die Leber sich beim Thorium als das empfindlichere Organ erwies.

Es ist also Benzol beim normalen Kaninchen jedenfalls ein schweres Nierengift in den Dosen, welche grössere Leukopenie hervorrufen.

Nach alledem kann man sagen, dass in der Tat, wio wir in Uebereinstimmung mit Selling fanden, das Benzol besonders electiv das Knochenmark schädigt, und dass sich hier das Knochenmark in der Tat in gewisser Beziehung ähnlich wie beim Thorium verhält. Das Knochenmark ist bei Benzol (nebst Niere und Leber) das empfindlichste und am meisten geschädigte Organ. Die Wirkung am Knochenmark ist indes doch sehr viel schwächer als bei Thorium, und während nach unseren Feststellungen beim Thorium hier besonders die hochdifferenzierten Granulocyten zuerst schwinden und durch das Restieren der Lymphoidzellen eine nachmalige Neubildung von Granulocyten möglich bleibt, scheint hier eher eine vermehrte Umbildung der Lymphoidzellen zu Granulocyten stattgefunden zu haben, insofern als die Lymphoidzellen zuerst verloren gegangen scheinen.

Die Blutzellen, soweit sie im Blut circulieren, werden hier aber nicht so geschädigt wie durch Röntgenstrahlen und Thorium, speziell persistieren beim Benzol, ganz im Gegensatz zu den Röntgenstrahlen, die Lymphocyten auffallend viel lünger als die Jeukocyten (während sie bei Röntgenoder Thoriumstrahlen zuerst verschwinden), womit harmoniert, dass wir die $\mathrm{Mil}_{z}$ und ihre Lymphknötchen beim Benzol im ganzen wenig geschädigt fanden. Die Granulocyten schwinden aber aus dem peripherischen Blut in Fällen von kurze Zeit hindurch verabfolgten grosseu Dosen in erster Linie nicht, wie Selling meint, ausschliesslich durch Leukolyse und verringerte Bildung aus dem Knochenmark, sondern neben der verringerten myelogenen Bildung besteht gelegentlich auch eine Ansammlung bzw. eine Flucht aus der Peripherie in die parenchymatösen Organe hinein, besonders in die Milz und Lebercapillaren mit ihrer verlangsamten Circulation.

Wir haben somit beim Benzol, auch in der stärkst ertragbaren Dosis, eine deutliche Wirkung auf die cursierenden Blutzellen selbst nicht mit Sicherheit wahrgenommen, fast in allen Fällen aber eine starke Nierenentzündung, die bei den grösseren Dosen zu schwersten Ent- 
zündungen und Schädigungen des Organs führen kann. (Beim Thorium finden wir die Leber empfindlicher als die Nieren.)

Unsere Feststellungen bringen also als neu dio leichte Vulnerabilität der Nieren gegenüber diesem Gift. Sie weichen von den Ergebnissen und Deutungen Sellings darin $a b$, dass wir bei unseren zwar kürzer fortgesetzten, aber mit grösseren Dosen angestellten Versuchen keine so hochgradige Atrophie des Knochenmarks, und eine greifbarere Atrophie des Lymphadenoidgewebes meist überhaupt gar nicht feststellen konnten, dass die Atrophie des Knochenmarks wesentlich auf einem Schwund der lymphoiden Markzellen beruhte, dio Granulocyten aber nur quantitativ vermindert erschienen; dass schliesslich die absolute und relative Leukopenie des peripheren Blutes hier und da zum Teil wenigstens mitbedingt wird durch eine blosse Ansammlung der Leukocyten zentral in den parenchymatösen Organen, besonders der Leber und Niere.

Es mögen jetzt noch kurz einige Versuchsprotokolle einer Reihe von Tierversuchen folgen, die später mit Kaninchen einer angeblich besonders widerstandsfähigen russischen Rasse vorgenommen wurden, um die Vergiftung eventuell längere Zeit hindurch aufrecht erhalten und durchfübren za können, und bei denen das Blut nur mikroskopisch, nicht durch Zählung geprüft worden war. Auch hier war durchweg ein rapider Leukocytensturz und eine starke Verarmung, wenn auch nicht totale Verödung des Blutes an Leukocyten feststellbar gewesen. Aber auch wo die polynucleären Spezialzellen vielfach ganz geschwunden schienen, persistierten immer noch einige lymphocytäre und besonders einige grosse unreife lymphoide Elemente.

Benzoltiere.

Kaninchen 266. Gewicht $970 \mathrm{~g}$.

Am 15. 11. subcutane Injektion von Benzol $3,0 \mathrm{ccm}$, Oleum olivarum $6,0 \mathrm{ccm}$.

16. 11. dasselbe.

18. 11. dasselbe.

19. 11. Exitus letalis. Das Tier war unter der Behandlung ausserordentlich abgemagert und hatte rom zweiten Tage an fast gar nichts mebr gefressen. Bei der Nekropsie erscheint die Milz ausserordentlich klein und schwärzlich, das Knochenmark sebr rot, Leber and Niere obne Besonderbeiten.

\section{Histologische Untersuchung.}

Knoohenmark: erscheint total atrophisoh, wie ausgepinselt, nur noch aus dem Reticulum und starkem Blutgehalt bestehond. Parenchymzellen sind völlig geschwunden.

Milz: erscheint wie ausgepinselt; besteht nur noch aus Reticulam und Reticumzellen; die Parenchymzellen feblen in Pulpa und Follikeln.

Niere: es besteht starke parenchymatöse Schädigung, stellenweise bis zur Nekrobiose, daneben Glomerulitis (Kernreichtum und Hyperämie der Glomerulusschlingen) nebst Exsudat im Kapselraum. Keine Blutangen.

Leber: zeigt partielle strichförmige Nekrosen, schwere parenchymatöse Schädigung. An manchen Partien erscheinen die Leberzellkerne ganz klein, verklumpt und pyknotisch, wäbrend das Zellprotoplasma ungefärbt ist.

Kaninchen 296. Gewicht $2070 \mathrm{~g}$.

Am 15. 11. Benzol 3,5, Oleum olivarum 6,0 subcutan. 
Am 16. 11. Benzol 3,5, Oleum olivarum 6,0 subcutan.

Am 18. 11. dasselbe.

Am 21. 11. dasselbe.

Am 23. 11. dasselbe. Gewicht an diesem Tage $1400 \mathrm{~g}$.

Am 24. 11. Exitus.

\section{Histologische Untersuchung.}

Knochenmark: zeigt neben ausserordentlich starker Gefässerweiterung und Anschoppung ausgesprochene Parenchymatrophie. Man sieht fast nur noch stromatische Elemente.

Milz: zeigt eine mässige Verkleinerung der Follikel, aber sonst keine wesentlich auffälligen Besonderheiten.

Nebennieren: obne Besonderbeiten.

Niere: starke Parenchymschädigung mit Oedem des gesamten Gewebes. Cylinder nicht wabrnebmbar.

Leber: Capillaren and grössere Gefässe nioht wesentlich erweitert, es finden sich kleinste circumscripte nekrotische Partien.

Kaninchen, Kopf blau. Gewicht $1130 \mathrm{~g}$.

21. 11. Benzol 2,0, Oleum olivarum 8,0 .

23. 11. Benzol 2,5, Oleum olivarum 8,0 .

25. 11. Benzol 2,5, Oleum olivarum 7,0 .

29. 11. Benzol 2,5, Oleum olivarum 7,0.

2. 12. Benzol 2,0, Oleum olivarum 8,0 .

3. 12. Exitus.

\section{Histologische Untersuchung.}

Knochenmark: es besteht bei starkem Blutgehalt, Erweiterung und Anschoppung der Gefässe eine starke Parenchymatrophie. Die Granulocyten orscheinen fast völlig geschwunden, neben den stromatischen Zellen finden sich nur noch einzelne lymphoide Elemente.

Milz: Follikel anscheinend verkleinert, aber nioht äbermässig atrophisch. Pulpa mit einer grossen Menge phagocytierender Sinusendothelien durchsetzt.

Nieren: das Gewebe erscheint stark ödematös geschwollen und von herabgesetzter Färbbarkeit des Kanälchenepithels.

Leber: zeigt zahlreiche und in diesem Falle auffallenderweise centrale Nekrosen.

Blinddarmappendix: entbält Coccidien, sonst ohne Besonderbeiten,

\section{Zusammenfassendes Ergebnis.}

Bei diesen Versuchen mit Tieren einer besonderen Rasse ergab sich in der T'at als constantes Ergebnis in einzelnen Fällen der Benzolvergiftung analog den Feststellungen Sellings eine schwere fast absolute Atrophie des myeloiden Knochenparenchyms mit einer sehr hochgradigen, wenn auch nicht absoluten und totalen Blutleukopenie; die Schädigung des lymphatischen Parenchyms, besonders in der Milz, ist auch hier im ganzen gering, jedenfalls bedeutend geringfügiger, als beim Mark, immerhin stellenweise etwas grösser als bei den früheren Kaninchen. Die schwere Knochenmarksschädigung ist aber auch hier in allen Fällen verbunden und sozusagen erkauft mit starker Reizung und zum Teil nekrotischer Alteration des Nierenparenchyms und nekrotischen Degenerationen der Leber. 


\section{Vergleich der Ergebnisse mit strahlender Energie und Benzol.}

Am Blut fand nach Röntgenisierung Heineke eine Leukopenie bis tausend durch völliges elektives Verschwinden allein der Iuymphocyten.

Ziegler Leukopenie nicht unter 2400, ebenfalls nur durch die Abnahme der Lymphocyten bis zu einem Prozentverhältnis von $1,4 \mathrm{pCt}$.

Bei Benzol fand Selling am Blut Leukopenie bis 700 Zellen durch Abnahme der verschiedenen Granulocyten und Monocyten. Er findet Lymphocytenzahlen von $32-86$ pCt.

Was die Veränderungen am hämopoetischen Apparat betrifft, so finden Ziegler und Heineke bei Röntgenstrahlen am Lymphadenoidgewebe eine Atrophie; am Myeloidgewebe findet Heineke ebenfalls Atrophie, Ziegler umgekehrt einen Reizungszustand.

Bei Benzol fand Selling eine Atrophie an Knochenmark und I, y mphadenoidgewebe, die aber am Lymphadenoidgewebe stärker ist. Er findet an den Lymphknötchen Pyknose und Kernzerfall, am Knochenmark völligste $A$ plasie. Neben fixen Elementen finden sich hier nur noch Lymphocyten und polyblastische Lymphoidzellen; diese sind am aller resistentesten und bleiben noch vorhanden, wenn alle anderen Knochenmarkselemente bereits verschwunden sind.

Wir sehen hieraus, dass nach Angaben der Autoren und im Gegensatz zu den Ausführungen von Selling keineswegs eine völlige Analogie und Gleichartigkeit der Wirkungen der Röntgenstrahlen und des Benzols besteht. Nach Röntgenstrahlen schwinden nach übereinstimmender Meinung der Autoren aus dem Blut die Lymphocyten, nach Benzol persistieren am längsten die Lymphocyten. Nach Röntgenstrahlen scheint eine Atrophie des Lymphadenoidgewebes, jedenfalls kein Reizzustand (Heineke, Ziegler), das konstante zu sein, verbunden anscheinend mit einer direkten oder indirekten Reizwirkung auf das Knochenmark ( $\mathrm{Ziegler}$ ); nach Benzol besteht fraglos eine Atrophie des Knochenmarks.

Das histologische Verhalten der Gewebe würde hiernach auch ganz gut den Blutbefund erklären: bei Röntgenstrahlen J ymphopenie, bei Benzol Leukopenie und relative Lymphocytose.

Gegenüber diesen bei allen Autoren konstanten Feststellungen dürften die von Heineke beobachtete Atrophie des Marks nach Röntgenstrahlen und die von Selling beobachtete Atrophie der Lymphknötchen bei Benzol von untergeordneter Bedeutung und durch Besonderheiten der Einzelfälle zu erklären sein.

Gegenüber den mitgeteilten Befunden der Autoren fanden nur wir (Pappenheim) bei Thorium absolute Ly mpho- und Leukopenie mit vollständiger Verödung des Knochenmarks bis auf spärliche lymphoide 7.llreste. Atrophie mässigen Grades der Lymphknötchen verbunden mit Pyknose und Karryorrhexis und bindegewebiger Zellumwandlung im Keimcentrum und in den interfolliculären Strängen; hochgradigen Zellschwund der Milzzellen in Pulpa und Follikel.

Bei Röntgenstrahlen im Blut keine völlige Zellentvölkerung, vielmehr Zahlen, die etwa den von Ziegler gefundenen entsprechen, also eine immerhin ziemlich beträchtliche Leukocytenabnahme, die fast allein 
auf Konto der Lymphocyten zu setzen ist, die stellenweise völlig aus dem Blut verschwunden sind. Am hämopoetischen Gewebe fanden wir keine irgendwie beträchtliche Atrophie der Follikel, dagegen einen gewissen Reizzustand am Knochenmark.

Unser röntgenologischer Blutbefund stimmt also überein mit Ziegler, desgleichen unser Knochenmarksbefund. Heineke hat demgegenüber stärkere Zellabnahme im Blut und Zellabnahme auch am Knochenmark beobachtet.

Bei Benzol fanden wir am Blut eine Zellabnahme bis auf 1000 , verbunden mit relativer Lymphocytose, gelegentlich mit bedingt durch centrale Granulocytenansammlung.

Am hämopoetischen Apparat keine besonders aufällige Milz- und Lymphknötchenatrophie, im Gegenteil hier eher öfters einen gewissen funktionellen Reizzustand; im Knochenmark dagegen stets eine mehr oder minder deutliche Atrophie, keineswegs stets so hochgradig wie beim Thorium und im Gegensatz zum Thorium und, abweichend von Sellings Angaben, vielfach mit einem Schwund der myeloiden Lymphoidzellen und einer Persistenz der Granulocyten einhergehend.

Also im Blutbefund der Benzolvergiftung stimmen wir mit Selling ziemlich überein, in bezug auf das hämopoetische Gewebe weichen wir insofern ab, als wir nicht lymphadenoide Knötchenatrophie fanden, sondern eher einen gewissen Grad von Hypertrophie der kleinzelligen Rundzellzone.

In der Milzpulpa war der Befund bei Röntgenstrahlen, Thorium und Benzol der gleiche; das atrophische Organ zeigt starke Pigmentbildung und Pigmentzellenanhäufung besonders in den Sinus.

Während wir indes bei den Röntgenstrahlen dazu kamen, eine lympholytische Wirkung jedenfalls auch auf das Blut als nicht unmöglich erörtern zu müssen, wird nach unseren Versuchen beim Benzol die absolute und relative Leukopenie erklärt durch die Atrophie des Knochenmarks und stellenweise durch die Ansammlung von Jueukocyten in den inneren Organen; die relative Lymphocytose ausserdem noch durch Neubildung in den lymphatischen Lymphknötchen. Während beim Thorium an sonstigen parenchymatösen Organen vor allem die Leber an erster Stelle geschädigt war, erwies sich hier beim Benzol die Niere als das empfindlichste und vulnerabelste Organ.

\begin{tabular}{|c|c|c|c|c|c|c|c|c|c|}
\hline & \multicolumn{3}{|c|}{$\mathrm{R} \ddot{\mathrm{n}} \operatorname{tg} \theta \mathrm{n}$} & \multicolumn{3}{|c|}{ Thorium } & \multicolumn{3}{|c|}{ Benzol } \\
\hline & Milz & Mark & Blut & Milz & Mark & Blut & Milz & Mark & Blut \\
\hline Selling & - & - & - & - & - & - & Atro & Atro- & Lymphopenie \\
\hline Heineke. & $\begin{array}{l}\text { A tro- } \\
\text { phie }\end{array}$ & $\begin{array}{c}\text { Atro- } \\
\text { phie }\end{array}$ & $\begin{array}{l}\text { Absolute und } \\
\text { relative Lym- } \\
\text { phopenie }\end{array}$ & - & - & - & - & pnie & - \\
\hline Ziegler & $\begin{array}{l}\text { Atro- } \\
\text { phie }\end{array}$ & $\begin{array}{l}\text { Reiz- } \\
\text { mark }\end{array}$ & $\begin{array}{l}\text { Relative Lym- } \\
\text { phopenie und } \\
\text { Leukocy tose }\end{array}$ & - & - & - & - & - & - \\
\hline $\begin{array}{l}\text { Pappen- } \\
\text { heim . }\end{array}$ & Normal & $\begin{array}{l}\text { Reiz- } \\
\text { mark }\end{array}$ & $\begin{array}{l}\text { Absolute und } \\
\text { relative } \\
\text { Lymphopenie }\end{array}$ & $\begin{array}{l}\text { Starke Lymph- } \\
\text { knötcben und } \\
\text { Pulpaatrophie }\end{array}$ & $\begin{array}{c}\text { Hochgradigste } \\
\text { Parenchym- } \\
\text { atrophie }\end{array}$ & $\begin{array}{l}\text { Absol. } \\
\text { Leuko- } \\
\text { penie }\end{array}$ & Normal & $\begin{array}{l}\text { Atro- } \\
\text { phie }\end{array}$ & $\begin{array}{l}\text { Absol. Leuko- } \\
\text { penie u. relat. } \\
\text { Lymphocytose }\end{array}$ \\
\hline
\end{tabular}


Der Unterschied zwischen Benzol- und Röntgenwirkung ist also nach unseren Versuchen: bei Röntgenstrahlen Reizmark und absolute Leukopenie (also relative Neutrocytose); bei Benzol Markatrophie mit absoluter Leukopenie plus relativer Lymphocytose (also relative Neutropenie).

\section{Benzinversuche.}

\section{Auszug aus einigen Protokollen. Wirkung anf das Blut.}

Kaninchen 186. Gewicht 1400 g. Bl ut: normale Verhältnisse. Leukocytenzahl (9800).

15. 9. $2,0 \mathrm{ccm}$ Benzin $+6,0 \mathrm{ccm}$ Oleum.

16. 9. Leukocytenzahl (7600). Es besteht relative Lymphocytose von $75 \mathrm{pCt}$. Die rorhandenen Granulocyten, Spezialzellen und Mastzellen ron normalem Aspekt. Benzin 2,0 ccm f Oleum olivarum 6,0 $\mathrm{cm}$.

17. 9. Leukocytenzahl (5100). Im Blut keine Mastzellen und Eosinophilie. Die Lymphocyten prävalieren ausserordentlich stark. Die spärlichen Granulocyten, die man findet, sind mikroskopisch obne Besonderheiten. Benzin 2,0 ccm + Oleum olivarum $6,0 \mathrm{ccm}$.

18. 9. Keine Untersuchang. Keine Einspritzang.

19. 9. Leukocytenzahl (3800). Starke Präralenz der Lymphocyten. Die vereinzelten Granulocyten, dio man findet, sind heute unreife Jugendformen mit einfacher gestaltetem plumpem Myelocytenkern und basophilem, sehr spärlioh granuliertem Protoplasma. B enzin $3,0 \mathrm{com}+$ Oleam olivarum $5,0 \mathrm{ccm}$.

21. 9. Leukocytenzahl (2700). Im mikroskopischen Präparat finden sich heute eigentlich nur noch Lymphocyten, ein einziger Promyelocyt wird gefunden.

22. 9. Benzin $4,0 \mathrm{ocm}+$ Oleum olivarum $4,0 \mathrm{ccm}$.

23. 9. Starke Lenkopenie (1800). Mikroskopisch finden sich im Blut überbaupt nur noch spärliche Lymphocyten. Benzin $6,0 \mathrm{ccm}$ + Olenm olivarum $4,0 \mathrm{ccm}$.

24. 9. Zählung ergibt 850 Leukocyten. Mikroskopisch finden sicb in 4 Präparaten 6 Lymphocyton. Benzin $8,0 \mathrm{ccm}+$ Oleum olivarum $10,0 \mathrm{ccm}$.

25. 9. Das Tier ist über Nacht gestorben.

Nekropsie: Knochenmark dunkelrot. Milz klein und schwärzlich. Nieren stark blutreich. Leber stark fettig.

Kaninchen 223. Gewicht $1500 \mathrm{~g}$. Blut zeigt normale Verlältnisse. Leukocytenzahl (11000).

25. 9. Benzin $5,0 \mathrm{ccm}+$ Oleum olivarum $5,0 \mathrm{ccm}$.

26. 9. Leukocytensturz auf 5000 . Relative Lymphocytose von $90 \mathrm{pCt}$. Benzin $6,0 \mathrm{ccm}+$ Oleum olivarum $6,0 \mathrm{ccm}$.

28. 9. Leukocyten (1900). Im Blut finden sich jetzt nur noch Lymphocyten, keine Mastzellen, keine Eosinophile, keine mononucleäre. Benzin 4,0 ccm + Oleum olivarum $6,0 \mathrm{ccm}$.

29. 9. Leukocyten 1200. Das Blut besteht überwiegend aus kleinen Lymphocyten. Die spärlichen Granulocyten, die man findet, sind unreife Vorstufen mit spärlicher unreifer Körnung und basophilem Plasma. Benzin 2,0 cen + Oleum olivarum $8,0 \mathrm{ccm}$. Leukocytenzahl (1400). Die Jugendformen der Spezialleukocyten haben etwas an Zahl zugenommen.

30. 9. Benzin $3,0 \mathrm{ocm}+$ Oleum olivarum $6,0 \mathrm{ccm}$.

1. 10. Das Tier, das trotz der mittelgrossen Benzindosen bei gutem Befinden und Fresslust ist, wird getötet.

Die Nekropsie ergibt makroskopisch an den Organen (Lunge, Leber, Nieren, Nebennjere) äusserlioh nichts Abnormes, speziell nicht an Leber und Nieren. Milz 
ist wohl entwickelt von normal roter Farbe. Knochenmark ist nur an den oberen Epiphysen gerötet.

Kaninchen 225. Gewicht $1760 \mathrm{~g}$. Leukocytenzahl (11900).

28. 9. Benzin $4,0 \mathrm{ccm}+$ Oleum olivarum $6,0 \mathrm{com}$.

29. 9. Leukocytenzahl (5900). Lymphocyten $95 \mathrm{pCt}$. $5 \mathrm{pCt}$. Granulocyten, meist im unreifen Zustand. Benzin $6,0 \mathrm{ccm}+$ Oleum olivarum $4,0 \mathrm{ccm}$.

30. 9. Dasselbe leukocytäre Blutbild. Benzin $8,0 \mathrm{ccm}+$ Oleum olivarum $6,0 \mathrm{ccm}$. In der Nacht Exitus.

Nekropsie: Die Nieren ziemlich blutreich, an Nebennieren und Lungen makroskopisch nichts Besonderes. Die Leber sieht stark verfettet und anāmisch aus.

Unsere Benzinversuche zeigen, dass dieser Stoff von gleich grossen Kaninchen relativ besser vertragen wird als Benzol, dass dagegen schon kleine Dosen dieses chemisch total differenten Stoffes ebenfalls eine Leukopenie mil relativer Lymphocytose, also denselben Blutbefund hervorrufen, den wir beim Benzol, aber erst bei relativ grösseren eingreifenderen Dosen gefunden hatten, dass wir dagegen eine Reizungshyperleukocytose in kleinen Dosen nicht hervorgerufen haben. Man könnte hieraus die Schlussfolgerung ziehen, dass das Benzin ein Stoff wäre, der weniger heftige allgemein neurotoxische Wirkung hervorruft als das Benzol, dagegen schon in kleineren harmloseren Dosen die gleiche spezifische und kräftige Wirkung auf die $\mathrm{Zu}$ sammensetzung des Blutes ausübt, die das gefährlichere Benzol erst in Dosen hervorruft, die der Dosis letalis schon sehr nahe liegen. Andererseits scheint es, als ob die spezifische Wirkung dieser beiden Stoffe auf die Leukocyten und den leukocytoblastischen Apparat weniger von der chemischen Konstitution, die doch ganz verschieden ist, als von dem physikalisch-lipolytischen Charakter abhängt. $\mathrm{Ob}$ und bis zu welchem Grade diese aprioristische Ansicht begründet ist, kann sich aber erst aus der histologischen Betrachtung der Organe ergeben, zu der wir jetzt übergehen wollen.

\section{Histologische Untersuchung.}

\section{Dip Wirkung anf die Organe.}

Kaninchen 186. Das Knochenmark der langen Röhrenknochen ist ausser ordentlich blutreich, die Gofässe prall gefüllt, keine freien Blutungen im Gewebe. Das Knochenmark ist ausserordentlich zellarm, ohne dass das qualitative Gewebsbild wesentlich verändert wäre. Speziell sind Granulocyten reichlich vorhanden, dagegen sind die Megakaryocyten ausserordentlich spärlich und geschrumpft, die lymphoiden Zellen fast völlig gescbwunden.

Milz: am histologischen Bild, speziell an den Follikeln nichts Abnormes, insbesondere keine Atrophie. Das Organ ist ausserordentlich blatreich und die Pulpa reich an Pigment.

Lungen: ohne Besonderheiten.

Leber: zeigt kleinzellige Infiltration geringen Grades des perilobulären Bindegewebes in den Gefassscheiden. Etwas centrale Stauung mit ziemlich viel Zellpigment.

Nieren: mässiger Blutreichtum. Der Bowmansche Kapselraum ist meist völlig verstrichen, hier und da im Kapselraum otwas zellfreies Exsudat. Die Glomeruli ziemlich zellreich. In den graden Harnkanälchen des Marks finden sich 
abgeschilferte Epithelien, in den gewundenen hyaline Cylinder. Sonst wohlerhaltene Gowebszeichnung.

Nebenaiere: ohne Besonderheiten. Cbromaffine Substanz nicht nebr vorhanden.

Gehirn und Rückenmark ohne Besonderheiten.

Es findet sich also neben recht erheblich starker Knochenmarksatrophie eine im Verhältnis zu Benzol mässige Leber- und Nierenreizung.

Kaninchen 223. Knochonmark: es besteht im Centrum des Diaphysenmarks ein geringer Grad deutlicher Atrophie.

Milz: obne jede Besonderbeit.

Darmfollikel des Appendix: ohno jedo Besonderheit, speziell Atrophie.

Lungen: intakt.

Lober: normal, aber mit granulocytärer Anschoppung in den Ge. fässen.

Niere: geringer Grad ron Rarefication des Epithelzellparenchyms.

Nebonniere: ohne Besonderheiten.

Kaninchen 225. Knochenmark: dasselbe ist ausserordentlich zellreich und zeigt ausgesprochene deutliche und starke Hyperplasie mit viel Megakaryocyten. Im Diaphysenmark keine Fetträume mehr vorhanden.

Milz: es besteht deutliche Lymphknötchenatrophie geringen Grades. Die Knötchen sind nicht so sehr zellarm als an Zabl gering. Die Pulpa ist deutlich hyperplastisch, ausserordentlich blutreich und in beginnender, aber klar erkennbarer myeloider Metaplasie befindlicb. In den Sinus zahlreicbe endotheloide Pbagocyten. Dicht unter- und innerhalb der stark infiltrierten Kapsel finden sich kleinere Stellen mit karyorrhektischem Kernzerfall.

Lymphknoten: es besteht deutliche Atrophie der Knötchen. Interfolliculär und in der Gegend der Keimcentren besteht starke Bildung von endotheloiden makrophagischen, meistenteils pigmenthaltigen, vielfach stark vacuolisierten Sinusendothelien. Auch hier besteht deutlicher Kernzerfall.

Leber: ohne stärkere parenchymatöse Störung. Zollen mit starker Fettinfiltration. In den Capillaren, die weder besonders erweitert, noch abnorm blutreich sind, finden sich zahlroiohe Granulocyten.

Niere: obne schweren Reizzustand. In den gradon Kanälchen etwas hyaliner Inbalt, in den Capillaren viel Granulocyten.

Nebennieren: obne Besonderbeiten.

Wir finden also auch hier bei den Benzintieren, und zwar öfter als bei den Benzoltieren eine Anschoppung von Granulocyten, besonders in der Leber, ferner einen stets leichteren, aber immerhin doch vorhandenen Reizzustand der Nieren.

Sehr aufällig ist besonders in dem. letzt geschilderten Fall das Verhalten des hämopoetischen Apparates. Hier haben wir, ganz so wie Selling es beim Benzol beschreibt, eine deutliche, wenn auch nicht hochgradige Atrophie der Lymphknötchen. Während aber Selling beim Benzol daneben auch Atrophie des Knochenmarks fand, haben wir gerade in diesem Fall keine solche, sondern im Gegenteil eine geringe Hyperplasie. Wo wir sonst Knochenmarksatrophie hatten, da fehlte uns die Lymphknötchenatrophie; hier, wo sie vorhanden ist, besteht umgekehrt Knochenmarkshyperplasie, und es ist so die Hyperplasie des Knochen- 
marks mit einer geringen generellen Atrophie lymphatischen Gewebes verknüpft.

Es ist schwer, diesen hyperplastischen Zustand zu erklären. Ist er die Folge der Atrophie im Sinne Zieglers oder ist die Atrophie der Lymphknötchen die Folge der myeloiden Hyperplasie im Sinne von Meyer-Heineke? Vielleicht handelt es sich auch hier infolge der kurzen Dauer der Versuche nur um einen initialen Zustand, wie derartiges auch Selling andeutungsweise bei seinen Benzolversuchen beschreibt.

Auffallend ist indes, dass dieser myeloiden Hyperplasie hier keine Hyperleukocytose des Blutes entspricht, wie Solling sio stets im Beginn seiner Benzolversuche mit kleinen Dosen beobachtet haben will; vielmehr fanden wir auch hier Leukopenie, und zwar fast stets mit Zellanschoppung der Capillaren in der Leber und Niere. Eine Hyperleukocytose haben wir nur bei sehr kleinen Dosen des Benzols gesehen, die aber bei grösseren Dosen bald einer Leukopenie wich und dann auch mit Knochenmarksatrophie einherging. In unserem Benzinfällen, wo wir alsbald grosse Dosen verabfolgten, ist das Fehlen einer Hyporleukocytose und das Auftreten von Leukopenie verständlich; und wenn diese Leukopenie, zum Teil wenigstens, nur durch blosse Zellconcentration in inneren Organen vorgetäuscht wurde, also gar kein Substrat im Knochenmark zu haben brauchte, so ist es verständlich, dass bei einem Versuch von nur kurzer Dauer, der infolge der grossen Dosen sehr rasch durch den Tod beendet wurde, als erster Ausdruck einer initialen Reizung myeloide Milzmetaplasie und Knochenmarkshyperplasie gefunden wird.

Es erweist sich also auch hier beim Benzin das Myeloidgewebe als das empfindlichste und zuerst reagierende hämopoetische Substrat; sie zieht ihrerseils die lymphatische Atrophie nach sich. Im Blut kommt es peripherisch zur Neutropenie, infolge Zellansammlung der Spezialzellen in den inneren Organen, und zur restierenden peripherischen relativen Lymphocytose.

Russische Kaninchen.

Kaninchen 245. Gewicht $1000 \mathrm{~g}$.

Am 15. 11. subcutane Injection ron Benzin 6.0 + Oleum olivarum 4,0.

16. 11. Benzin 5,0, Oleum olivarum 5,0 .

18. 11. Benzin 6,0 , Oleum olivarum 4,0 .

19. 11. Exitus. Bei der Aułopsio fällt besonders das ausserordentlich rote Knocheninark auf.

\section{Histologische Untersuchung.}

Knochenmark: das Parenchym erscheint deutlich in beginnender Hyperplasio begriffen; das Fettgewebe ist äusserst zellreich, und die Fettareolen sind verschwunden.

Milz: das Organ ist ausserordentlich dünn und atrophisch, die Follikel erscheinen atrophisch, die Pulpa zellarm mit starker Bindegewebsvermehrung und zahlreichen Granulocyten.

Niere: das Gewebe ist stark ödematös und zeigt eine ausgesprochene parenchymatöse Epithelschädigung (Quellung, schlechte Färbbarkeit). Die Glomeruli heben sich kaum von der Umgebung ab.

Leber: die stark erweiterten Capillaren erscheinen angefüllt mit poly. nucleären Spezialleukocyten, sonst keine pathologische Gewebsveränderung. 
Kaninchen 228. Gewicht $1050 \mathrm{~g}$.

Am 15. 11. sabcatane Injektion ron Benzin 6,0, Oleum olivarum 4,0.

16. 11. Benzin 5,0 , Oloum olivarum 5,0 .

18. 11. Benzin 5,0 , Oloum olivarum 4,0 .

20. 11. Exitus.

\section{Histologische Untersuchung.}

Knochenmark: das makroskopisch äusserst rote lymphoide Mark erscheint mikroskopisch ausserordentlich blutreich, seine areoläre Structur verwischt. Es besteht deutlich beginnende Gowebshyporplasie mit Vermehrung der gekörnten Elemente. Megakaryocyten werden nur spärlich gefunden.

Milz: die Milz ist ausserordentlich lang and dünn, die Follikel sind zum Teil keimcentrumbaltig; die Palpa ist in myeloider Metaplasie begriffen and zeigt zahlroiche Plasmazellen.

Niөre: die normale Gewebsstructur ist duroh stärkstes Oedem völlig verwischt und verquollen; die Glomeruli heben sich von der Umgebung kaum ab; die Lumina der Harnkanälchen sind fast völlig verstrichen, doch finden sich weder Cylinder noch Blutinhalt im Innern.

Leber: Contralgefasss aud Capillaren erweitort and strotzend mit Blut gefüllt, in den erweiterten Capillaren finden sich zahlreiche polynucleäre Spezialleukocyten.

Nebonnioren: ohne gröbere Besonderheiton.

Kaninchen (hinten blau).

21. 11. Benzin 5,0, Oleum olivarum 5,0.

23. 11. dasseibe.

25. 11. Benzin 6,0 , Oleum olivarum 4,0 .

29. 11. Benzin 5,0, Oleum olivarum 5,0 .

2. 12. dasselbe.

4. 12. dasselbe.

5. 12. Das Tier ist äusserst decrepide. Es besteht ein starkes Hautemphysem in der Gegend der Injektionsstelle im Nacken, welches bei Druck knistert. Beim Einschnitt entleøren sich Benzingase. Im Blut fehlen polynucleäre Granulocyten völlig, dagegøn finden sich noch ziemlich reichlich Lymphocyten und grosse Lymphoidzellen.

6. 12. Exitus.

\section{Histologische Untersuchung.}

Knochenmark: die Gefässe sind stark erweitert und blutreich; das Gewebo zeigt bei erbaltener areolärer Structur eine A tropbie and Zellarmut mässigen Grades. atrophisch.

Blinddarm: ohne Besonderheiten, speziell sind die Lymphknötchen nicht

Leber: die Gefässe stark erweitert und mit Blat gefüllt. In den erweiterten Capillaren finden sich polynucleäre Leukocyten, wenn auch nicht allzu zahlreich. In den grossen Gefässquerschnitten sieht man auch lymphoide Blutzellen.

Niere: auch hier ein deutlich vorbandener Grad von parenchymloser Epithelzellschmelzung.

Auch bei diesen Benzinversuchen findet sich also eine starke Leukocytenverarmung des Blutes, doch erstreckt sich diese wesentlich nur auf die polynucleären Spezialleukocyten. Auch hier ist eine elective Einwirkung auf das Knochenmark unverkennbar, doch ist dieselbe graduell weitaus geringer als beim Benzol und stellt sich meist nur in Form eines Reizzustandes dar. Eine hochgradigere 
Atrophie des Knochenmarks irgendwie nennenswerten Grades wie beim Benzol wurde in dieser Versuchsreihe, selbst bei den ziemlich hochgewählten Dosen, nicht erzielt, meistens bestand vielmehr ein Reizzustand mit beginnender Hyperplasie. Dagegen erschien die Milzpulpa nicht stark affiziert.

Die Leukopenie des peripheren Blutes stellte sich hier fast stets als eine vorgetäuschte Pseudoleukopenie heraus, insofern als die Lebercapillaren bei ihrer verlangsamten Circulation mit polynucleären Leukocyten angeschoppt erschienen. Die Blutlymphocyten und der lymphatische Apparat zeigten keine Beeinträchtigung, der letztere sogar gelegentlich eine Art von Reizungszustand. Das Leberparenchym war niemals geschädigt, wohl aber constant die Niere. Während diese aber bei Benzol mehr strichweise beginnende Nekrosen zeigten, fand sich hier beim Benzin, besonders bei Verabfolgung grosser Dosen, fast constant ein ausserordentlich starkes Gewebsödem.

\section{Zusammenfassendes uber das Benzin und Vergleich der Benzol- und Benzinversuche.}

1. Wir finden, dass auch das Benzin nicht ganz gleichgültig für die Nieren ist, dass Nieren und Leber aber viel weniger geschädigt werden als bei Benzol;

2. dass der hämopoetische Apparat, speziell das Knochenmark, prinzipiell anscheinend in gleicher und in gleich elektiver Weise wie bei Benzol affiziert wird, und zwar schon bei relativ schwachen Dosen. Der erreichte Grad der Affektion ist aber bei weitem geringer als beim Benzol. Bei relativ zu geringen Dosen wird stets nur Reizmark erzielt.

Wir fanden also, dass Benzin scheinbar prinzipiell gleichartig wie Benzol auf das Blut, sowie gewisse parenchymatöse (Nieren) und hämopoetische Apparate (Knochenmark) wirkt, indes ist die Schädigung am Knochenmark hier weniger schwer und eingreifend als beim Benzol, desgleichen an den Nieren $z w$ ar extensiver aber essentiell weniger eingreifend. Im Blut herrscht ebenfalls Leukopenie mit relativer Lymphocytose, am Knochenmark aber fast kaum jemals schwerere Atrophie, an den Nieren leichter Grad parenchymatöser Reizung. Die Leukopenie des Blutes ist hier beim Benzin fast meistens eine bloss regionäre PseudoLeukopenie.

Es scheint daher, bei prinzipieller Gleichartigkeit der Wirkung, das Benzin selbst von grösseren Dosen wesentlich nur eine Reizwirkung zu erzeugen und daher nur in gewisser Hinsicht (vielleicht für perniciöse Anämie) gewisse Vorzüge zu haben.

\section{E. Einiges über die Combination von Benzin und Benzol.}

Es sollte versucht werden, ob die relativ harmlose Wirkung kleiner Benzoldosen durch kleine Benzindosen in geeigneter und besonders erfolgreicher Weise zu der Höhe grosser wirksamer, allein aber gefährlicher Benzoldosen ohne die unerwünschte Nebenwirkung dieser gesteigert werden könnte. 
Kaninchen 219. Blut $=$ Leukocyten 10500 . Prozentverhältnisse normal.

\section{Blutuntersuchang.}

15. 9. Benzin + Benzol aa $2,0 \mathrm{ccm}$, Oleum olivarum $4,0 \mathrm{ccm}$.

16. 9. Es besteht im mikroskopischen Präparat ein leichter Grad von Hyperleukocytose, an dem die Lymphocyten und Loukocyten in annäbernd normalen Prozentverhältnissen beteiligt scheinen. Auch die Mastzellen sind ziemlich zahlreich. Benzol + Benzin aa $2,0 \mathrm{ccm}$, Oleum olivarum $4,0 \mathrm{ccm}$.

17. 9. Die Zahl der Leukocyten hat abgenommen. In der Zählkammer und im mikroskopiscben Präparat werden keine polynucleären Leukocyten mehr gefunden. Es finden sich nur ganz vereinzelte kleine Lymphocyten und ein Monocyt. Heute keine Injektion.

18.9. Im mikroskopischen Präparat finden sich nur noch vereinzelte kleine Lymphocyten und vereinzelte Monocyten, keine Leukocyten mehr. Benzol + Benzin aa 2,0 ccm, Oleum olivarum $4,0 \mathrm{ccm}$.

19. 9. Im mikroskopischen Präparat keine polynucleären Leukocyten mebr. Hier und da ein paar vereinzelte Lymphocyten und Mastzellen. Benzol + Benzin aa $2,0 \mathrm{ccm}$, Oleum olivarum $4,0 \mathrm{ccm}$.

21. 9. Die wenigen Lymphocyten, die gefunden werden, befinden sich meistens im Reizungszellzustand, daneben finden sich heute auch wieder einige Granulocyten, dieselben sind im unreifen Zustand begriffen mit plumper Kernform, basophilem Protoplasma und spärlicher Körnung. Heute keine Injektion.

22. 9. Benzin + Benzol aa $2,0 \mathrm{ccm}$, Oleum olivarum $4,0 \mathrm{ccm}$.

23. 9. Wieder äusserst hochgradige Leukopenie und nur noch vereinzelte Lymphocyten. Injektion von Benzol 2,0 ccm + Benzin 4,0 ccm, Oleum olivarum 5,0 ccm.

24.9. In eineu Objektträger-Blutpräparat werden $z$ wei Lymphocyten und ein unreifer Granulocyt mit basophilem Plasma und spärlichster Körnung gefunden. Eine heute vorgenommene Zählung ergibt 980 Leukocyten. Injektion von Benzol 2,0 ccm + Benzin $4 \mathrm{ccm}$, Oleum olivarum 5,0 $\mathrm{cm}$. Das Tier stirbt in folgender Nacht. Bei der Nokropsie findet sich ein dunkelrotes Knochenmark der langen Röhrenknochen. Die Milz ist sebr klein, atrophisch und schwarz. Leber, Nieren äusserlich ohne Besonderheiten.

Wir sehen also in der Tat, dass das Benzin in kleinen Dosen die Wirkung des Benzols anscheinend unterstütat, und dass auch hier wieder eine grössere Benzoldose den sofortigen Tod zur Folge hat.

\section{Histologische Untersuchung.}

Knocbenmark: kolossal blutreich und äusserst zellarm. Der normale histologische Bau ist verwischt. Megakaryocyten werden nicht gefunden. Lymphoidzellen äusserst spärlich.

Milz: ohne Besonderheiten, speziell keine Lymphknötchenatrophie.

L eber: leichter Grad perilobulärer Gefässwandinfiltration. Sehr starker Blutreichtum des Organs.

Nieren: das Organ ist sehr blutreicb, besonders in den sehr kernreichen Glomerulischlingen. Der auffallende Befund ist, dass sich in der Gegend der Intermediärzone in den geraden Harnkanälchen eine strichförmige Randzone in dunkelgrüner Färbung zeigt, die sich bei stärkerer Vergrösserung als eine feinkörnige pigmentähnliche Substanz innerhalb und ausserbalb der 'Zellen erweist (Benzolurie?) ${ }^{1}$ ). Im übrigen bestebt allenthalben ein glasig vacuolisierter Zustand parencbymatöser

1) Der Befund findet sich in beiden Nieren. Da in keinem anderen der völlig gleichmässig behandelten Organe ähnliches gefunden war, scheinen mir Formolniederschläge ausgeschlossen werden zu können. 
Zelldegeneration. Die Harnkanälchen sind frei von Blut, dagegen finden sich fleckund strichweise Blutungen frei im Gewebe, sowohl in Mark wre Rinde.

Nobennieren: starke Rindenatrophie, im Mark keine chromaffine Substanz. Gehirn und Rü ckenmark: ohne Besonderheiten.

Kaninchen 329. Bei diesem Tier wurde Benzol und Benzin teils abwechselnd und teils combiniert gegeben. Blut: Normale Verhältnisse. Leukocyten (10800). Prozentverhältnisse normal.

3. 10. Benzol $0,5 \mathrm{ccm}$, Oleum olivarum $6,0 \mathrm{ccm}$.

4. 10. Benzol $0,5 \mathrm{ccm}$, Oleum olivarum $6,0 \mathrm{ccm}$.

5. 10. Benzol $1,0 \mathrm{ccm}$, Oleum olivarum $6,0 \mathrm{ccm}$.

7. 10. Benzol $1,0 \mathrm{ccm}$, Oleum olivarun $6,0 \mathrm{ccm}$.

8. 10. Blut: Ausgesprochene Hyperleakocytose (19200) durch éinseitige Verwehrung der polynucleären Spezialzellen, die 65 pCt. betragen; daneben zahlreiche grosse bucbtkernige Lymphoidzellen $(11 \mathrm{pCt}$.) sowie Mastzellen $(6 \mathrm{pCt}$.). Eosinophile feblen. Benzin $2,0 \mathrm{ccm}$, Oleum olivarum $6,0 \mathrm{ccm}$.

9. 10. Die Hyperleukocytose ist geschwanden, Leukocytensturz auf 10900 , mit relativer Lymphocytose von $42 \mathrm{pCt}$., besonders der kleineren Lymphocyten. Benzin $2,0 \mathrm{ccm}$, Benzol $1,0 \mathrm{ccm}$.

10. 10. Es besteht keine absolute Hyperleukocytose, dagegen starke polynucleäre Spezialleukocytose (45 pCt.). Auftreten spezialkörniger Jugendformen mit plumperen Kernen (Metamyelocyten und Myelocyten, z. T. mit basophilem Protoplasma und spärlichen oft basophilen Körnchen (Promyelocyten). Eosinopbile fehlen. Injektion ron 3 proz. Natron nucleinicum + Alttuberkulin aa $0,5 \mathrm{ccm}$.

11. 10. Es besteht keine Hyperleukocytose (10200). Im Blutbild keine pathologischen Lymphocytenformen; die Granulocyten sind aussobliesslich spezialgekörnt; keine Eosinophile, keine Mastzellen. Viele weisen Vorstufen mit plumpen Kernen mit rarefizierter, z. 'T. basophiler Körnung im basophilen, auffallend stark vacuolisierten Plasma auf und gleichen dadarch degenerierten Mastzellen ${ }^{1}$ ).

12. 10. Keine Untersuchung, keine Injektion.

13. 10. Das Kaninchen ist vergangene Nacht gestorben.

Nekropsie: Das Diaphysenmark der langen Röhrenknochen sieht dunkel himbeergeleerot aus, in den Epiphysen ist nur das Mark der oberen dunkelrot, das der unteren fettig graurot.

Milz kiein, atrophisch.

Nebennieren sehr klein.

An Nieren und Lungen makroskopisoh niobts Besonderes. Die Organe erscheinen indes sehr blutreich.

Die Leber sieht makroskopisch und auf dem Querschnitt sohwer verändert aus und zeigt kleine submiliare, gelblich graue Sprenkelung in diffuser Dissemination durch das ganze Organ.

\section{Histologische Untersuchung.}

Knochenmark: Hochgradiger Blutreichtum und starke Abnahme des parenchymatösen Zellgewebes. Die Zahl der Zellen ist vermindert, aber die qualitative Zusammensetzung nicht wesentlich rerändert. Megakaryocyten in spärlicher Zabl rorbanden, zum T'eil verklampt. Lymphoide Zellformen fehlen fast ganz.

Milz: keine Follikelatrophie, in der Peripherio der Follikel bestebt eine beginnende Metaplasie, die Sinus sind angefüllt mit breitleibigen rundkernigen Pigmentophagen.

1) Ganz so wie das Pappenhein und Szécsi beim Meerschweinchen nach Bebandlung mit Saponin und Nucleinsäure gefunden und beschrieben haben. Fol. haem. 1912. Bd. 13. 
Nebennieren and Langen: ohne Besonderbeiten.

Leber: von der Poripherie der Läppchen ans gogen das Centram fortschreitend, finden sich ausgedehnte Nokrosen ${ }^{1}$, die stellenweise grösser sind als die erhaltenen Lzberparenchymreste. In dem gut erbaltenen Lāppchen besteht Staung mit Atrophio der Leberzellbälkchen und fettige Degeneration. Zahlreiche polyoucleäre Spezialleakocyten finden sioh innerhalb der Capillaren der nekrotischen, abor anch der orbaltonen Partien. Diese peripheren Nekrosen dürften dafür sprechen, dass eine resorptive Vergiftung vom Darm aus stattgefunden bat. Jedenfalls zeigen sie, dass auoh hier gegenüber dem Thorium $\mathrm{X}$, wo einmal nentrale Nekrosen beobachtet warden, ein wesentliober Unterschied nicht zu bestehen scheint.

Niere: Es finden sich woiter Partien, in denen die Epitheizellen nur ganz schwach färbbar sind, nie zerfallen und atrophisch aussehen. Freie Blutangen bestehen wieder nicht.

\section{Ergebnis der Benzol- und Benzin-Combination.}

In bezug auf den hämopoetischen Apparat (Milz, Knochenmark) ist etwas besonders Hochgradiges, steter als mit Benzol allein, auch nicht erzielt worden. Dagegen erscheinen die Leber- und Nierenschädigungen weit stärker ausgeprägt, als bei Benzol oder Benzin allein.

\section{Sehlussergebnisse.}

Das Ergebnis unserer experimentellen Untersuchungen ist folgendes:

Die Benzolwirkung hat mit der Thoriumwirkung gemein, dass eine Atrophie des Knochenmarks und eine Verringerung der Leukocytenzahl im peripheren Blut hervorgerufen wird. Bei diesen Gemeinsamkeiten der Hauptwirkung bestehen indes doch grosse Unterschiede:

1. Sowohl die Atrophie des Knochenmarks wie die Leukopenie ist graduell weitaus geringer als beim Thorium.

2. Es bestehen aber auch qualitative Unterschiede.

a) Beim Thorium betrifft die viel grössere Knochenmarksatrophie wesentlich die granulierten Zellen, die völlig und absolut schwinden, beim Benzol umgekehrt die lymphoiden Zellen, während die Granulocyten nur unwesentlich an Zahl reduziert erscheinen.

b) Eine Atrophie des Lymphadenoidgewebes, wie sie Selling beobachtet haben will, und wie sie beim 'Thorium zweifellos bestebt, haben wir bei unseren Benzolversuchen nicht feststellen können.

c) Während bei Thorium-, Radium- und Röntgenstrahlen die Lymphocyten im Blut zuerst angegriffen scheinen, obwohl der lymphadenoide Apparat histologisch weniger affiziert scheint wie der myeloische, fanden wir beim Benzol, ebenso wie Selling, als Abweichung von der Thoriumwirkung, dass die Lymphocyten in der Circulation am resistentesten persistierten, entsprechend der fast fehlenden Veränderung am Lymphadenoidgewebe.

d) Die absolute und relative Granulocytopenie des Blutes entspricht ja anscheinend der Knochenmarksatrophie, wird aber, zum Teil wenigstens, mitbedingt durch eine centrale Ansammlung der

1) Siebe Tafel I. 
Leukocyten in den Capillaren der Leber, weniger der Niere und der Milz.

e) Während bei 'grossen Thoriumdosen in erster Linie die Leber von parenchymatösen Organen affiziert erscheint, fanden wir hier beim Benzol die Niere häufiger im Reizzustand, und während wir beim Thorium in der Leber gelegentlich centrale Nekrosen fanden, fanden wir hier beim Benzol einigemale ausgedehnte peripherische Nekrosen.

Was das Benzin und seine Wirkung anbetrifft, so ist sie, trotz chemischer Differenz der Stoffe, bej den physikalisch verwandten Eigenschaften in ihren Manifestationen auf Blut, hämopoetischen Apparat und parenchymatöse Organe anscheinend prinzipiell gleichartig mit dem Benzol, aber graduell wesentlich geringer.

Auch hier absolute und relative Granulopenie, nicht mit Anschoppung der Granulocyten in den inneren Organen. Auch hier öfters Knochenmarksatrophie auf Kosten der lymphoiden Zellen und Fehlen stärkerer Grade von Lymphadenoidgewebsatrophie.

Auch hier fast stets gewisse Grade von Nierenreizung.

Es wird besser und in grösseren Dosen rertragen als das Benzol; während bei letzterem eher die Leber gefährdeter scheint als die Niere, scheint beim Benzin das umgekehrte der Fall zu sein.

Wir können zum Schluss also sagen: 1. Benzol und Benzin sind kein concurrenzfähiger Ersatz für Thorium, wohl aber geeignet, in passenden Fällen dasselbe zu unterstützen. 2. Es könnte vielleicht auch das Benzin in seiner Wirkung auf Blut und blutbildenden Apparat in mancherlei Hinsicht von ähnlichem Wert wie das Benzol sein.

\section{Erklärung der Abbildnngen auf Tafel I.}

Fig. 1. Kaninchenleber nach Benzin-Benzol mit perilobulären Nekrosen. Färbung May-Giemsa-Essigsäure nach Pappenheim.

Fig. 2. Kaninchenleber nach Thorium mit centralen Nekrosen. 